\title{
Ideological Asymmetries in Motivated Reasoning and the Mechanisms of Attitude Polarization: A Two-Wave Survey Experiment
}

\author{
Davide Morisi, Collegio Carlo Alberto, Italy $^{1}$ \\ Matthew H. Goldberg, Yale University, USA \\ John T. Jost, New York University, USA
}

Paper prepared for the 2020 Annual APSA Conference

This version: September 13, 2020

\begin{abstract}
Are there specific motives that lead individuals to become extreme in their political attitudes after exposure to information? Can these motives explain recent evidence that attitude polarization occurs more on the conservative than the liberal side? We propose that two mechanisms, related to relational motives to engage in social conformity and epistemic motives to reduce uncertainty, might contribute to answering these questions. We used experimental manipulations to induce relational and epistemic motives in a two-wave survey experiment, in which we exposed participants to balanced information pertaining highly salient political issues in the U.S. Our results suggest that relational motives to maintain homogenous social networks are highly pertinent to how people, especially political conservatives, process information and make up their minds about important social and political issues. When exposed to social cues indicating where liberals and conservatives stand on specific issues, the two groups became further apart in their attitudes. Furthermore, we observed that, in the presence of social cues, conservatives were more likely to develop extreme attitudes than liberals, triggering asymmetric polarization. Contrary to our predictions, however, we did not obtain consistent evidence of increased ideological polarization when epistemic motives to reduce uncertainty were present, although we found that conservatives (and not liberals) displayed a stronger confirmation bias in the evaluation of political arguments when uncertainty was high (compared to low).
\end{abstract}

\footnotetext{
${ }^{1}$ Corresponding author: davide.morisi@ carloalberto.org
} 
Healthy democratic politics and genuine public deliberation require, at the very minimum, that people are "exposed to oppositional political perspectives" (Mutz 2006: 6) and are "willing to revise preferences in light of discussion [and] new information" (Chambers 2003: 309). However, in the political domain this basic requirement is too seldom met. Numerous studies show that, when individuals process political information, they are often motivated to maintain their existing beliefs (Jost, Hennes, and Lavine 2013) and reach a particular conclusion (Kunda 1999; Taber and Lodge 2006). It is certainly possible that motivated reasoning processes such as these would contribute to the phenomenon of increasing attitude polarization following exposure to conflicting political information (e.g., Ditto et al. 2019; Hart et al. 2009; Lord, Ross, and Lepper 1979). ${ }^{2}$ At the same time, recent work calls into question the extent to which attitude polarization occurs in response to counter-attitudinal information (Guess and Coppock, 2018)

We propose that the desire to reach a particular conclusion, as posited by theories of motivated reasoning, might not be chronically active or powerful enough to cause citizens to engage in attitude polarization. Other motives, when activated, might play a more prominent role in exacerbating differences of opinions among citizens; these include the desires to reduce uncertainty and share a sense of reality with like-minded others (Jost, Ledgerwood, and Hardin 2008). Because these epistemic and relational motives tend to be stronger among political conservatives than liberals (Jost, van der Linden, Panagopoulos, and Hardin, 2018), they could help to explain why large-scale studies find that conservatives and Republicans are more likely than liberals and Democrats to possess online social networks that resemble "echo chambers" (Barberá et al. 2015) and to express more extreme attitudes following exposure to opposing views on social media (Bail et al. 2018).

We designed a two-wave survey experiment to investigate two mechanisms that could trigger motivated reasoning in the processing of political information and contribute to attitude polarization. Drawing on accumulating evidence that, in comparison with liberals, conservatives exhibit stronger epistemic and relational motives to reduce uncertainty and opinion deviance (for a review

\footnotetext{
${ }^{2}$ In the present research program we do not address other "types" of political polarization, such as elite polarization (Hetherington 2001), affective polarization (e.g., Hobolt, Leeper \& Tilley 2020; Iyengar, Lelkes, Levendusky, Malhotra \& Westwood 2019), or aggregate opinion polarization (Baldassarri and Gelman 2008).
} 
see Jost 2017), we further tested whether these mechanisms would lead to an ideological asymmetry in attitude polarization. The first mechanism focused on relational motivation: the desire to reduce within-group heterogeneity and establish like-minded social networks, which we manipulated by providing participants with social cues indicating the issue positions of liberals and conservatives. The second mechanism focused on epistemic motivation: the desire to reduce uncertainty and attain a sense of order, structure, and closure, which we manipulated by raising the perceived level of evidential uncertainty pertaining to salient political issues.

\section{Various Contributors to Motivated Reasoning}

According to several prominent social psychological theories of motivated reasoning, when people process information they are either motivated to be accurate or to reach a particular conclusion (Kunda 1990; Nir 2011; Taber and Lodge 2006). In other words, people may process new information in order to satisfy "accuracy goals," that is, "the desire to form accurate appraisals of stimuli" (Hart et al. 2009: 557) or "directional goals," which might be self-serving, group-serving, or system-serving (Jost, Hennes, and Lavine 2013). When it comes to contentious political issues, people may seek out belief-consistent information and assign greater weight to information that confirms prior beliefs in comparison with information that contradicts those beliefs (e.g., Kahan 2015; Knobloch-Westerwick et al. 2015; Redlawsk 2002; Taber, Cann and Kucsova 2009). These types of behaviors, which are often observed in research in psychology and political science, are taken to indicate the presence of confirmation bias in the evaluation of information, that is, a form of directional motivated reasoning (for reviews see Nickerson 1998; Taber and Lodge 2016).

People may be motivated to reach a particular conclusion for many different reasons, including desires to maintain their beliefs, values, opinions, and social relationships. In a recent experiment assessing Republicans' attitudes toward climate change, Bayes and colleagues (2020) manipulated participants' motivational states so that they were focused on accuracy concerns, the protection of their values, or a defense of their social identity. The pattern of results showed that messaging was especially (or only) effective when the message was matched to the participant's motivational state. For example, when participants were induced to focus on their moral values, a message emphasizing those values significantly increased belief in climate change and pro-environmental behavioral intentions. The same message had no effect when participants were put in a different (non-value-oriented) motivational state. 
In line with the investigation by Bayes and colleagues (2020) as well as multifaceted theoretical accounts of motivated reasoning (Jost, Hennes, and Lavine 2013; Leeper and Slothuus 2014), we propose that the desire to preserve one's own pre-existing beliefs (Ditto et al. 2019) is only one of several psychological factors that could influence people responses to counter-attitudinal evidence on salient political issues (see also Baron and Jost 2019). At least two additional sources of motivation - namely, relational and epistemic motives for conformity and closure, respectively - could influence the processing of counter-attitudinal information. Furthermore, an analysis of motivated reasoning that takes into a count these additional motives is not only more comprehensive, it also may help to explain why and when ideological asymmetries in attitudes polarization are to be expected.

\section{Hypothesized Roles of Relational and Epistemic Motives in Confirmation Bias and Attitude Polarization}

Relational motivation in the present context refers to the desire to share a sense of reality with likeminded others and to maintain a relatively homogeneous social network (e.g., Jost, van der Linden, Panagopoulos, and Hardin, 2018). This motivation would manifest itself in terms of increased conformity to in-group norms, among other things. Although people are likely to possess multiple group identities (e.g., Dickson and Scheve 2006; Klar 2013; Tajfel \& Turner 1986), in the political sphere the most relevant form of social identification typically is a person's partisan (or, in some cases, ideological) identification, as documented by long-standing research since The American Voter (Campbell et al. 1960). Experimental research on party cues demonstrates that people are willing to change their mind on salient economic and political issues to better align their own views with the official party position (Bisgaard \& Slothuus 2018; Brader, De Sio, Paparo, \& Tucker, 2020; Coan, Merolla, Stephenson \& Zechmeister 2008; Druckman, Peterson and Slothuus 2013; Kam 2005).

According to Petersen and colleagues (2013), party cues trigger motivated reasoning, because they activate "a group-based motivation to appear loyal to the policy line of 'their' party" (p. 833). Relational motives to maintain group solidarity might be activated not only when people receive information about where their preferred party stands, but also (and perhaps especially) when they learn where other in-group members like them stand, that is, when they receive social cues. Research on the effects of exposure to public opinion polls, which are a common source of 
information about the political environment, reveals that voters may change their own opinions and voting intentions after learning about the opinions and intentions of other voters (for a review see Moy and Rinke 2012).

In the present research program we focused on contentious political issues, that is, issues for which there is a reasonably strong ideological divide in the United States. Therefore, we expected that providing information about where the majority of liberals and conservatives stood on these issues would trigger both liberals' and conservatives' desires to conform to in-group norms. These desires, in turn, should increase motivated reasoning when it comes to the evaluation of political arguments. More specifically, we hypothesized that in the presence (vs. absence) of social cues, providing information about liberals' and conservatives' positions on salient issues would lead both liberals and conservatives to exhibit stronger confirmation biases in information processing (H1A) and more attitude polarization (H1B).

In addition to the relational motive to engage in social conformity, we anticipated that a second mechanism - namely the epistemic motive to reduce uncertainty and attain a sense of order, structure, and closure (Jost 2017) —would also influence responses to counter-attitudinal information. When uncertainty surrounds the available evidence pertaining to a specific issue - as when the evidence is not very strong or is hotly contested - individuals should be less likely to be swayed by new, counter-attitudinal information, compared to a situation in which the new evidence is clear, strong, and widely accepted. In other words, when there is a great deal of uncertainty with respect to a given issue, people might cling even more strongly to their pre-existing beliefs. Consistent with this line of reasoning, a large body of research suggests that motivated directional biases are more impactful when information is ambiguous or open to multiple interpretations (e.g., Kruglanski et al., 2012; Kunda, 1990). We therefore hypothesize that when subjective uncertainty is higher (vs. lower), both liberals and conservatives would exhibit stronger confirmation biases in information processing $(\mathbf{H 2 A})$ and more attitude polarization $(\mathbf{H 2 B}){ }^{3}$

\footnotetext{
${ }^{3}$ In the experiment we manipulated the degree of uncertainty surrounding new information that individuals received. There is therefore the possibility that in the high uncertainty condition individuals would discount the new information altogether, because they might consider it too uncertain to have any epistemic value. This, in turn, would lead us to expect that attitudes would not change under conditions of high uncertainty. We included this alternative hypothesis in the study pre-registration.
} 


\section{Ideological Asymmetries in Relational and Epistemic Motives}

There is good reason to assume that relational and epistemic motives would contribute to motivated reasoning in general following exposure to counter-attitudinal information. At the same time, these factors can also help to explain why motivated reasoning might be more prevalent among conservatives than liberals, at least under some circumstances. As noted above, there is evidence that the online social networks of conservatives are more ideologically homogenous than those of liberals (Barberá et al. 2015; see also Boutyline and Willer 2017). Furthermore, several studies suggest that conservatives and Republicans are more likely to exhibit selective exposure to pro-attitudinal information and selective avoidance of counter-attitudinal information (e.g., Garrett 2009; Iyengar et al. 2008; Parmelee and Roman 2020; Stroud 2011; Vraga 2015) and to engage with fake news and political misinformation (e.g., Basol, Roozenbeek, and van der Linden 2020; Benkler, Faris, Roberts, and Zuckerman, 2017; Grinberg et al. 2019; Guess, Nagler, \& Tucker, 2019; Guess, Nyhan, \& Reifler, 2020; Hjorth and Adler-Nissen 2019; Roozenbeek and van der Linden, 2019), in comparison with liberals and Democrats.

In the context of a survey experiment, Bail and colleagues (2018) randomly assigned Democrats and Republicans to either a control condition or a treatment condition in which they were offered a financial incentive to follow a bot (i.e., an automated account) on Twitter that would retweet 24 messages each day for one month. Unbeknownst to participants (in advance), the bots consistently retweeted messages that were ideologically incongruent; Democrats were assigned a conservative bot, whereas Republicans were assigned a liberal bot. Results revealed an ideological asymmetry: Republicans became more extreme (polarized) in their views, whereas Democrats did not. However, Bail and colleagues were at a loss to explain the asymmetry, concluding that, "[p]erhaps the most important limitation to our study is that we were unable to identify the precise mechanism" explaining polarization only on the Republican side (ibid. p. 5, emphasis added).

In the experiment reported here, we sought to fill the theoretical gap exposed by previous research, including the work of Bail and colleagues (2018) by homing in on two possible mechanisms, namely relational and epistemic motives, as described above. Identifying precise mechanisms could also help to explain why some studies have failed to detect partisan or ideological differences in information processing biases (Collins, Crawford, and Brandt 2017; Ditto et al. 2019; Frimer, Skitka, and Motyl 2017; Iyengar and Hahn 2009; Kahan 2013; Petersen et al. 2013). In an effort to reconcile conflicting results arising from the use of different research paradigms, 
we propose that motivated reasoning processes should be stronger among conservatives than liberals under certain conditions, that is, when relational and epistemic motives are engaged by the information processing task.

This theoretical logic is consistent with a voluminous research literature demonstrating that, as noted above, conservatives are more strongly motivated by epistemic and relational concerns pertaining to certainty and conformity, in comparison with liberals. For instance, conservatives score higher than liberals on measures of uncertainty avoidance, intolerance of ambiguity, cognitive and perceptual rigidity, and personal needs for order, structure, and closure (Jost 2017). Conservatives also place greater emphasis than liberals on conformity, group loyalty, and social cohesion (Caprara, Schwartz, Capanna, Vecchione, and Barbaranelli, 2006; Cavazza and MucchiFaina, 2008; Jost, Basevich, Dickson, and Noorbaloochi, 2016; Piurko, Schwartz, and Davidov, 2011; Schwartz, Caprara, and Vecchione, 2010). In addition, they are more likely to be influenced by implicit social cues and sources who are similar to them and to prefer a strong sense of shared reality with like-minded others (Jost, van der Linden, Panagopoulos, and Hardin, 2018; Stern, West, Jost, and Rule, 2014). Consistent with these observations, an experiment by Bullock (2011) demonstrated that Republicans were more likely than Democrats to be influenced by partisan cues when it came to forming new policy preferences. Likewise, a survey of over 16,000 Americans by Goldberg and colleagues (2020) revealed that beliefs about climate change were more closely tied to perceived social norms among friends and family members for conservatives than liberals.

Drawing on all of this as background, we expected that conservatives would be more likely than liberals to engage in motivated reasoning under conditions that triggered relational and/or epistemic motives. More specifically, we hypothesized that in the presence (vs. absence) of social cues, conservatives would exhibit stronger confirmation biases in information processing (H3A) and more attitude polarization $(\mathbf{H 3 B})$, in comparison with liberals. Likewise, we hypothesized that in the presence (vs. absence) of high levels of informational uncertainty, conservatives would exhibit stronger confirmation biases (H4A) and more attitude polarization (H4B) than liberals. 


\section{Method}

\section{Participants}

We conducted an online study in two waves using a sample of participants recruited by Prolific. A total of 2,227 respondents completed the first wave between October 15 and October 17, 2019. After approximately two weeks we re-contacted all the selected participants, except 62 respondents who failed a number of basic quality checks in Wave $1 .{ }^{4} \mathrm{~A}$ total of 1,835 respondents participated in the second wave, which lasted from October 30 to November 2, 2019. We performed several additional quality checks. We decided to exclude from our sample 19 respondents who failed a basic attention check similar to the one included in Wave 1, and an additional 194 respondents who spent too little time to complete the study or read the passages. ${ }^{5}$ Thus, our final sample includes a total of 1,641 participants. Importantly, there were no statistically significant differences in the number of people who failed the quality checks across group conditions (see Table A1 in Appendix), and the results are similar to what is reported here if we include all of these respondents in the analysis.

Our sample differs from the population of adult U.S. citizens because it includes more females than males $(55 \%)$, more young people (median age $=33$ ), and large percentages of selfidentified White Americans (82\%) and highly-educated respondents (55.8\% with at least a bachelor's degree). More than half of the sample (57\%) described themselves as liberal, while one-third (33\%) described themselves as conservative, and the rest as moderate or possessing no ideology. For summary statistics, see Table A2 in Appendix.

\footnotetext{
${ }^{4}$ At the end of Wave 1, we included a basic attention check in which we asked respondents to recall the main issue presented in the questionnaire. A total of 30 respondents failed to provide the correct answer and were therefore not recontacted in Wave 2. In addition, we excluded three respondents who took the survey twice, 20 respondents who spent less than one minute to complete the entire survey, and 9 respondents who replied "Don't know" to the attitude question.

${ }^{5}$ More specifically, we excluded respondents who spent less than two minutes to complete the entire study, were in the bottom five percent of the distribution with respect to time spent reading the introductory passages (including the treatments), and spent less than 15 seconds on the screen including one passage and related questions. We were able to perform these quality checks for respondents assigned to the "no information" condition as well, because they read the same texts included in the "information" condition, but only after replying to the attitude question.
} 


\section{Design and Measures 6}

At the beginning of Wave 1, participants were welcomed and given a brief, general description of the tasks that were to be completed during the study. Next they answered several socio-demographic questions (e.g., sex, age, education, race/ethnicity, perceived socio-economic status). Afterward, participants completed the standard ideological self-placement item used in the American National Election Studies: "We hear a lot of talk these days about liberals and conservatives. Here is a seven-point scale on which the political views that people might hold are arranged from extremely liberal to extremely conservative. Where would you place yourself on this scale?" with response options ranging from Extremely liberal (1) to Extremely conservative (7), with an additional option of I haven't thought much about this.

After answering these questions, participants in the first wave were randomly assigned to read about either universal healthcare or "border barriers" (expanding barriers such as the one between the U.S. and Mexico to fight illegal immigration) and then asked to report their attitudes on the issue in question. These answers provide us with a measure of initial (or prior) attitudes. To measure participants' attitudes about universal healthcare we asked "On a scale from 0 to 10 , where 0 means "strongly against" and 10 means "strongly in favor", how strongly in favor or against are you with implementing a universal healthcare system, meaning publicly-funded health coverage for all American citizens?" Answers were provided on scale with points 0, 5 and 10 labelled respectively as "strongly AGAINST", "neither against nor in favor", and "strongly IN FAVOR," respectively. In the case of border barriers we asked "how strongly in favor or against are you with expanding border barriers against illegal immigration," using the same 0-10 response scale. We also asked them how relevant the issue was for the U.S. in comparison to other issues, also on a scale from 0 to 10 .

We selected the issues of universal healthcare and border control because we sought to include one issue that was especially important to liberals and one that was especially important to conservatives. The two issues are different enough to provide a reasonable test of the stability and generalizability of results across more than one issue. Following our analysis of the 2016

6 All primary hypotheses detailed in the introductory section were preregistered on OSF (https://osf.io/3qsw7/?view_only=f02a646f66754e338114e36462cb60f6). Therefore, we use one-tailed tests for those hypotheses. All other analyses were considered to be exploratory, and we use two-tailed tests for them. The questionnaire and stimuli are provided in Appendix B. 
ANES pre-election study, ${ }^{7}$ and a pilot test that we conducted with a convenience sample of 228 respondents, we determined that universal healthcare and border control were both extremely relevant issues for the respondents (see Appendix C). As anticipated, universal healthcare was significantly more relevant for liberals than conservatives, and expanding border barriers was significantly more relevant for conservatives than liberals. Furthermore, liberals and conservatives held substantially divergent views on both topics. By replicating the same experimental design with two different issues we aimed to rule out the possibility that hypothesized treatment effects were driven exclusively by the perceived relevance of the issues.

To avoid potential practice or demand effects, we collected data for Wave 2 approximately two weeks after Wave 1. In Wave 2, we included our experimental manipulations as illustrated in Figure 1. Respondents were randomly assigned to one of four groups within each issue block, so that those who were assigned to read about universal healthcare in Wave 1 read passages and answered questions related to that issue in Wave 2, and the same was true of those who were assigned to read about the border control issue. Each group includes around 200 respondents.

Figure1. Design of the experiment

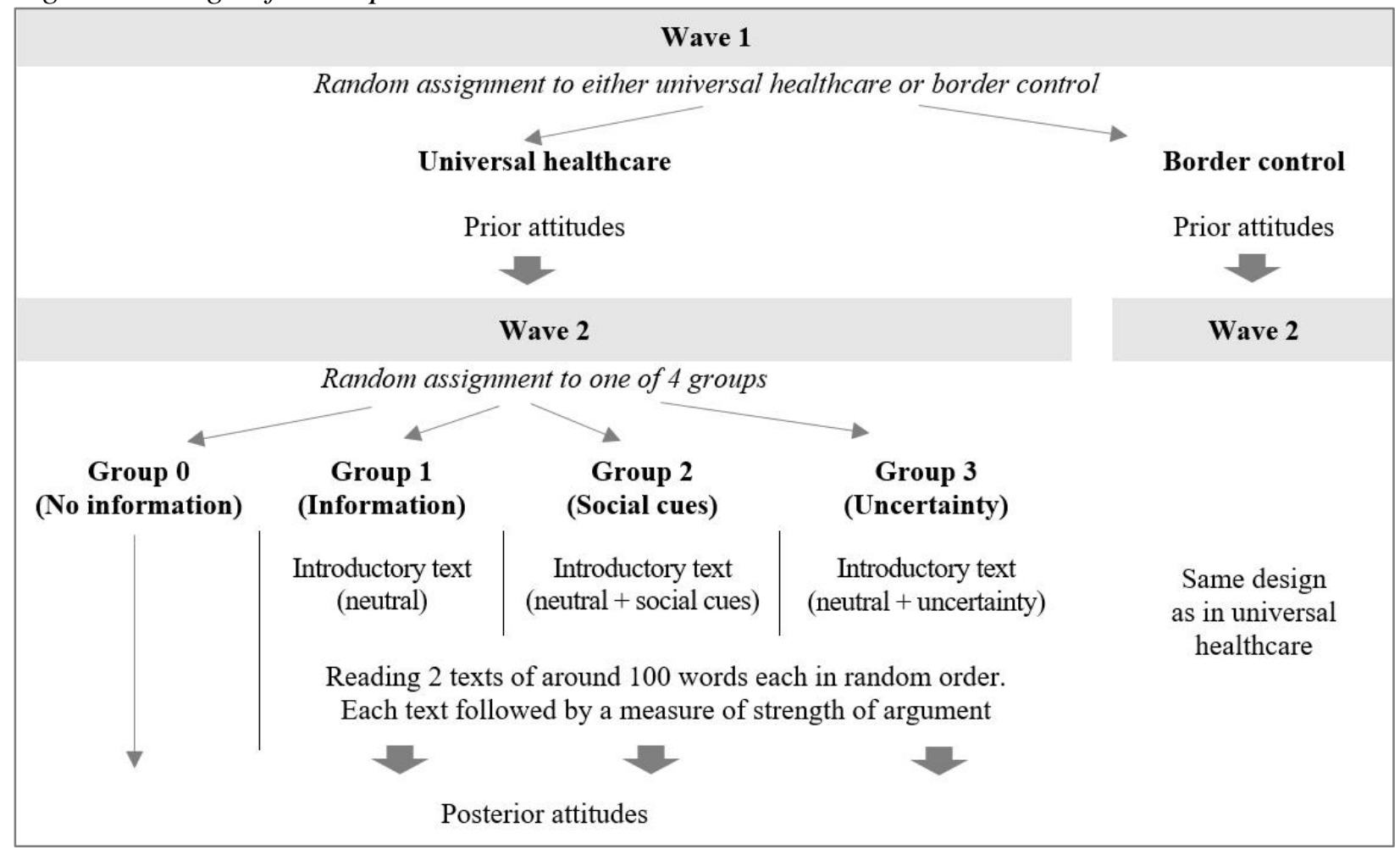

\footnotetext{
${ }^{7}$ We inspected liberals and conservatives' opinions in response to several prompts, including a question about governmental versus private health insurance schemes and a question about approving/opposing building a wall on the U.S. border with Mexico.
} 
Participants assigned to the no-information condition (Group 0) simply proceeded to answer the attitude questions. By comparing responses in this condition to those in the information condition, we can determine whether motivated reasoning was asymmetrical — that is, whether liberals and conservatives processed information and update their attitudes differently - simply in the presence of two-sided information, but in the absence of experimental manipulations of social cues and uncertainty salience. If our argument is correct that motivated reasoning should be asymmetrical only when relational or epistemic motives are activated, we would not expect to see significant differences between liberals and conservatives when participants simply receive two-sided information with no labels attached (information condition) compared to the no information condition.

Respondents assigned to the information condition (Group 1) read the following introductory sentences:

On the next screens we will ask you to read two short texts about implementing a universal healthcare system, meaning publicly-funded health coverage for all American citizens / border control and expanding border barriers against illegal immigration. The information included in each text is taken only from publicly available, reliable sources.

People assigned to the social cue condition (Group 2) read the same introductory paragraph, with an additional sentence reminding them where most liberals and conservatives stand regarding the selected issue.

On the next screens we will ask you to read two short texts about implementing a universal healthcare system, meaning publicly-funded health coverage for all American citizens / border control and expanding border barriers against illegal immigration. The information included in each text is taken only from publicly available, reliable sources.

However, citizens are greatly divided in their support for these arguments, with liberals and conservatives having opposite opinions on this issue. A majority of liberals are strongly in favor of introducing a universal healthcare system, but a majority of conservatives strongly oppose universal healthcare / A majority of conservatives are strongly in favor of expanding border barriers against illegal immigration, but a majority of liberals strongly oppose expanding border barriers.

Respondents assigned to the uncertainty salience condition (Group 3) read the same introductory paragraph and were also reminded that there is substantial uncertainty concerning the issue. 
On the next screens we will ask you to read two short texts about implementing a universal healthcare system, meaning publicly-funded health coverage for all American citizens / border control and expanding border barriers against illegal immigration. The information included in each text is taken only from publicly available, reliable sources.

However, there is an intense debate on this topic and experts strongly disagree on whether implementing universal healthcare / expanding border barriers would either benefit or damage the United States. There is also a lot of uncertainty on the estimated costs of a universal healthcare system, and it is not clear what kind of impact it would have on increasing life expectancy / There is also a lot of uncertainty on the estimated costs of expanding border barriers, and it is not clear what kind of impact they would have on reducing illegal immigration.

Next respondents read two short passages of approximately 100 words each (presented in random order), containing one argument in favor and one argument against the issue proposal. We selected these arguments after pre-testing 8 arguments in favor and 8 arguments against each of the two issues (universal healthcare and border control), as contained in publicly available sources of information. After reading each text, the respondents replied to a 0-10 scale measuring the "strength" of the argument-whether the argument was perceived as weak or strong — using a question administered by Taber and Lodge (2006). ${ }^{8}$

After the foregoing, respondents replied to the same attitude question included in Wave 1, so that we could now measure their posterior attitudes. Finally, we asked all respondents to recall the main topic of the passages they just read to check on how attentive they were in processing the arguments.

\section{Method of analysis}

In the main analysis we rescaled responses to the attitude questions to range from -5 to 5 , and inverted the polarity for the issue of border control so that interpretation for both issues would be the same. Thus, our outcome variables ranged from -5 , for those who were strongly against universal healthcare and strongly in favor of expanding border barriers, to 5, for the opposite combination of responses, with a value of 0 corresponding to neutral (or indifferent) attitudes.

\footnotetext{
${ }^{8}$ The question was worded as follows: "How weak or strong do you believe the argument contained in this text is? Please note: we want to know how weak or strong you believe the argument is, not whether you agree or disagree with the argument." Answers could range from 0 (extremely weak) to 10 (extremely strong).
} 
To compare liberals and conservatives, we recoded responses to the ANES item into three categories: "Liberals" (corresponding to "Extremely liberal," "Liberal," and "Slightly liberal”), "Conservatives" (corresponding to "Extremely conservative," "Conservative," and "Slightly conservative"), and a residual category in which we included both "Moderates" and people who responded "Don't know."

Furthermore, in Wave 2, before presenting the information task, we administered a selection of six attitude questions created by the Pew Research Center (2012) and used by Zell and Bernstein (2014) to tap into respondents' opinions on core social and economic issues (e.g., welfare, gay rights, abortion; see Appendix B for the full list of questions). We then combined three items into an index of economic conservatism, and the other three into an index of social conservatism (Cronbach's alpha $=0.71$ and 0.76 , respectively). Following a procedure adapted from Carmines, Ensley, and Wagner (2012), we defined those with below-median values on both indices as "liberals" (34\%), those with above-median values on both indices as "conservatives" (42\%), and the others as either "Libertarian" $(12 \%)$ or "Communitarian" (12\%). ${ }^{9}$ Despite being strongly correlated with the self-reported measure of ideology (Cramer's V $=.50, \mathrm{p}<0.001$, Pearson's chisquare test), this alternative measure has two key advantages: first, it allows us to infer the respondents' ideology based on their actual positions on core issues, instead of relying on self-reported ideological placement, and, second, it allows us to identify those with clear liberal and conservative positions in both social and economic domains. The strong correlation between responses on this issue-based measure and the ideological self-placement confirms that respondents were able to identify their own ideological orientation in a meaningful way (see also Azevedo, Jost, Rothmund, \& Sterling 2019).

We analyzed the data using standard OLS regressions. In the main models, we regressed respondents' posterior attitudes, as reported in Wave 2, on indicators for treatment assignment with Group 1 (information) as the reference category, adjusting for the lagged dependent variable, that is prior attitudes in Wave 1 (Keele \& Kelly 2006). In each model we also adjusted for sociodemographic covariates (gender, age, education level, White-only race, and census regions), which may increase the precision of the estimates (Angrist and Pischke 2009: 23-24; Gerber, Green, and

\footnotetext{
${ }^{9}$ Following Carmines et al. (2012), Libertarians have liberal positions on social issues and conservative positions on economic issues, while Communitarians have conservative positions on social issues and liberal positions on economic issues.
} 
Shachar 2003: 547) under certain conditions (Kam \& Trussler, 2017). Balance checks indicated that there were no differences between groups regarding the distribution of covariates (see Table A3 in Appendix A). In Appendix A we summarize the results of additional robustness checks in which we exclude both covariates and the lagged dependent variable and obtained substantially similar results (see Appendix A).

\section{Results}

Before testing our hypotheses, we present descriptive results from Wave 1 . On a scale from 0 to 10 , both issues, on average, were considered by our sample to be fairly relevant in comparison with other public issues, although universal healthcare $(\mathrm{M}=7.6,90 \% \mathrm{CI}$ : 7.5-7.8) was considered to be more relevant than border control (M=5.4, 90\% CI: 5.2-5.6). Similarly, the respondents were, on average, more in favor of implementing universal healthcare (M=7.2, 90\% CI: 7.1-7.4) than expanding border barriers ( $\mathrm{M}=4.4,90 \% \mathrm{CI}$ : 4.2-4.6). When we calculate average levels of issue relevance and initial agreement by ideology, we observe stark differences between liberals and conservatives. As Figure 2 shows, the issue of universal healthcare was substantially more relevant for liberals than conservatives, whereas border control was substantially more relevant for conservatives than liberals. Furthermore, liberals were largely in favor of implementing universal healthcare, and conservatives were strongly against it. The opposite pattern held for border control: conservatives were largely in favor of expanding border barriers against illegal immigration, and liberals strongly opposed this measure. 
Figure 2. Issue relevance and attitudes by ideology (Wave 1)

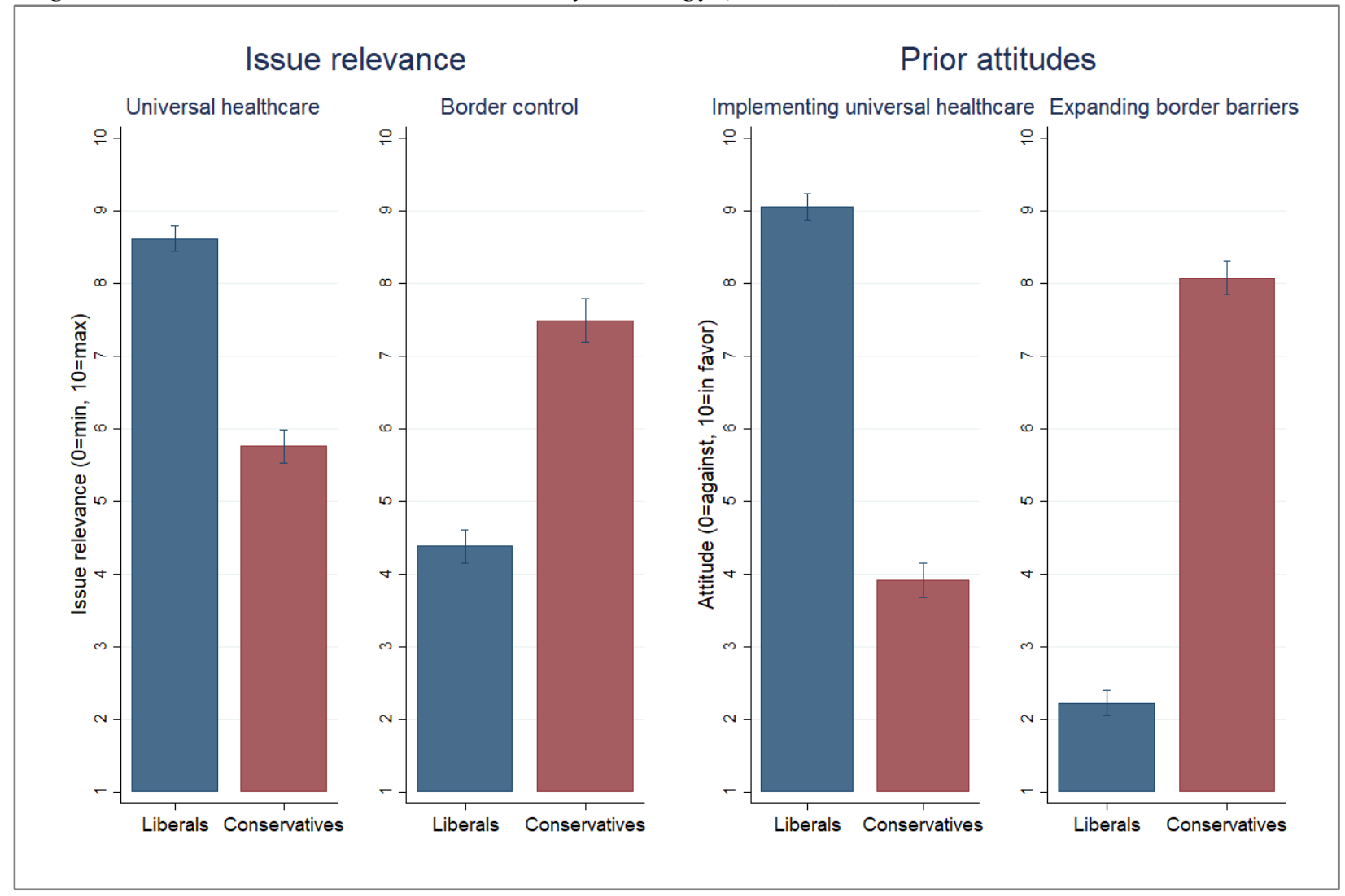

Note: Average levels based on OLS regression models in Table A4 controlling for gender, age, education level, race (White-only vs. others), and census regions. Data from Wave 1 . Vertical bars are $90 \%$ confidence intervals.

\section{Treatment effects on confirmation bias}

Now we turn to the effects of our experimental treatments on evaluation of information, based on the questions about the "strength of the argument" that were asked immediately after each text. Figure 3 illustrates the "gap" in the evaluation of pro versus con arguments for both liberals and conservatives. We created this measure by subtracting the evaluation of con arguments from the evaluation of pro arguments on the original 0-10 scale, and then inverting the polarity for the issue of border control, and finally rescaling the final scores from -5 to 5 . Thus, in the case of universal healthcare, positive values indicate that the respondents found the argument supporting universal healthcare stronger than the opposite one (and vice versa for negative values). In the case of border control, positive values indicate that the respondents found the argument against expanding border barriers stronger than the opposite one (and vice versa for negative values). Those who considered 
both arguments as equally strong would receive a value of 0 , and numbers that are greater than zero (in absolute terms) would indicate a larger gap in the evaluation of the two arguments.

If we first focus on the information condition only, we see that both liberals and conservatives displayed a confirmation bias in the evaluation of information, insofar as they gave greater weight to information that was supportive of their pre-existing opinions than to information that ran counter to them (Nickerson 1998, 178). Liberals found the arguments supporting universal healthcare and opposing expansion of border barriers to be more convincing than the corresponding counter-arguments, whereas conservatives showed the opposite pattern.

Figure 3. Confirmation bias in the evaluation of arguments by treatment conditions and ideology

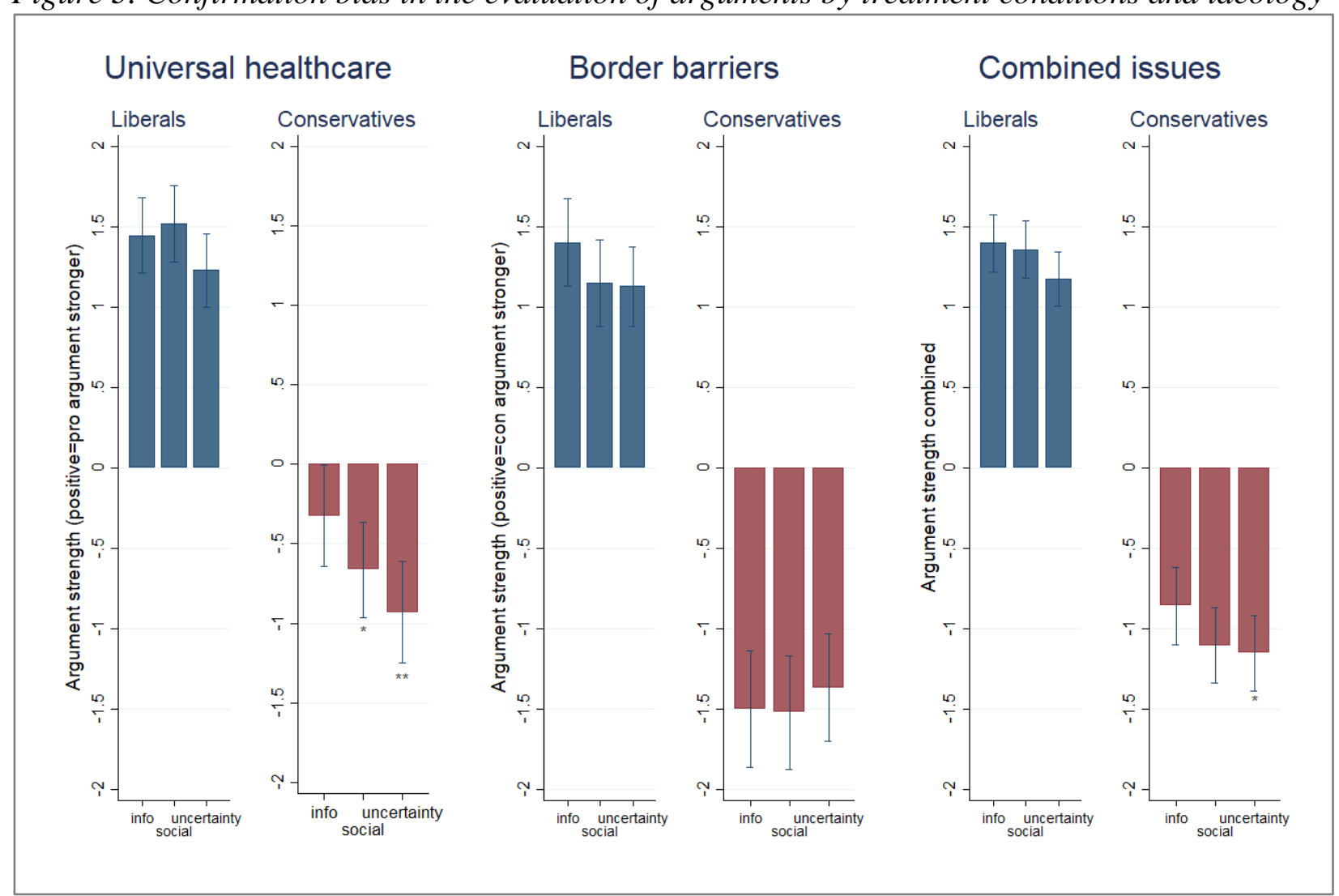

Note: Difference in the evaluation of pro and con arguments by treatment conditions and ideology. Positive values indicate stronger evaluation of pro universal healthcare/anti border barriers arguments versus relative counterarguments, and vice versa for negative values. Average levels based on OLS regression models 2, 4 and 6 in Table A5 controlling for gender, age, education level, race (White-only vs. others), and census regions. P-values for the difference between treatment conditions vs. information. $* \mathrm{p}<0.1, * * \mathrm{p}<0.05, * * * \mathrm{p}<0.01$ (one-tailed). Vertical bars are $90 \%$ confidence intervals. 
At the same time, liberals and conservatives reacted differently to the presence of social cues and uncertainty salience. As shown in Figure 3, when social cues or uncertainty were present, conservatives exhibited a stronger confirmation bias in the evaluation of pro-attitudinal arguments concerning universal healthcare, compared to the information-only condition (left-hand plot). That is, when conservatives were reminded of where the majority of liberals and conservatives stood on the issue of universal healthcare, or when they were reminded that there is substantial uncertainty surrounding the costs and benefits of publicly-funded health coverage, they judged the arguments supporting their pre-existing opinions on universal healthcare to be even stronger (on average). In the case of border barriers, however, there were no differences across conditions (center plot). The effect of uncertainty salience (but not social cues) remained statistically significant when responses to both issues were combined (right-hand plot). For liberals, the presence (vs. absence) of social cues and uncertainty salience either had no effect or, in some cases, a diminishing effect on confirmation bias. ${ }^{10}$

In summary, then, we did not find support for the general hypotheses that social cues (H1A) and uncertainty (H2A) would lead both liberals and conservatives to display stronger confirmation biases in the evaluation of information. This is largely due to the fact that the manipulations did not affect liberals' evaluations of the arguments. However, we did observe differences between liberals and conservatives. When we compare the effect of social cues between liberals and conservatives, we find that confirmation bias is 0.3 points (on a 0-10 scale) larger among conservatives (compared to liberals), although the difference is just above the $90 \%$ threshold of statistical significance ( $\mathrm{p}=0.13$, column 6 in Table A5). In the case of uncertainty, we find that confirmation bias is 0.5 points (on a $0-10$ scale) larger among conservatives, and the difference is statistically significant ( $\mathrm{p}=0.02$, column 6 in Table A5). These findings bring partial support to our hypothesis H3A and full support to our hypothesis H4A that social cues and uncertainty salience increase confirmation bias among conservatives (but not liberals).

\footnotetext{
${ }^{10}$ When we replicated the analysis using the alternative (issue-based) measure of ideology, we observed that the confirmation bias increased only among operational conservatives in the presence of either social cues or uncertainty salience, compared to the information only condition. These effects were driven mainly by the arguments pertaining to universal healthcare (see Table A6 in Appendix A).
} 
These findings lend some support to the idea that there is an ideological asymmetry in confirmation bias due to underlying differences in the motivations to maintain homogenous social networks (relational motives) and reduce uncertainty (epistemic motives), as proposed by Baron and Jost (2019). However, the fact that the asymmetry was mostly driven by one of the two issue suggests that there may be contextually specific factors at work. One possible explanation for this pattern of results is that conservatives were less subjectively certain in their beliefs about the effectiveness of implementing universal healthcare (vs. expanding border barriers), and this uncertainty led them to engage in a compensatory form of confirmation bias. We return to this possibility below.

\section{Treatment effects on posterior attitudes}

Next we investigated whether and, if so, how social cues and uncertainty salience influenced participants' attitudes about universal healthcare and border barriers. We first inspected the average effect of the experimental conditions on the entire sample, and we observed that, compared to the no information condition (Group 0), exposure to two-sided information (Group 1) reduced support for implementing universal healthcare by 4.2 to 5.4 percentage points (corresponding to 0.12 to 0.15 standard deviations) depending on model specifications (see Table A7). This is largely the result of liberals moderating their attitudes on universal healthcare in the presence of counterattitudinal information, by becoming less supportive of publicly-funded health coverage, as shown in the left-hand plot of Figure 4. Exposure to two-sided information, however, did not influence overall levels of support for expanding border barriers. There were no overall effects of exposure to social cues or uncertainty salience on respondents' attitudes. This is perhaps not surprising in light of the possibility that - if social cues and uncertainty salience contribute to attitude polarization by pushing liberals and conservatives toward more extreme positions, as hypothesized - these variables should not affect the average level of attitudinal support for the sample as a whole.

To test our more specific hypotheses, we therefore introduced interaction terms between experimental condition assignment and self-reported ideology in regression models. Table 1 summarizes the results. The interaction coefficients tell us whether the "distance" between liberals and conservatives on the two issues changed relative to the information-only condition (Group 1). To 
begin with, the negative coefficient of the interaction term "Information X Conservatives" in columns 3 and 4 indicates that liberals and conservatives polarized after reading a balanced (twosided) set of arguments about expanding border barriers, in comparison with the no information condition. This finding is in line with evidence of the polarizing effect of new information (e.g., Taber \& Lodge 2006). However, presenting two-sided information alone did not polarize liberals' and conservatives' attitudes with respect to universal healthcare, and the effect was not significant when both issues were combined.

Turning now to the effects of social cue exposure, the interaction term "Social cues $\mathrm{X}$ Conservatives" consistently shows that liberals and conservatives become more polarized in their attitudes when they were reminded of where the two groups stood on the issues. The effect was larger (and statistically significant) in the case of universal healthcare. Depending on model specifications (columns 1 and 2), the presence (vs. absence) of social cues increased the gap between liberals and conservatives on universal healthcare by 0.53 to 1.1 points on a $0-10$ scale (corresponding to 0.15 and 0.30 standard deviations). When we combined both issues (columns 5 and 6), we saw that social cues increased the gap between liberals and conservatives by 0.35 to 0.85 points on a $0-10$ scale (corresponding to 0.10 and 0.24 standard deviations). These findings support hypothesis H1B, namely that the presence of social cues would exacerbate ideological polarization.

Contrary to hypothesis $\mathrm{H} 2 \mathrm{~B}$, however, we obtained no evidence that when uncertainty salience was higher liberals and conservatives would show increased polarization, as the interaction term “Uncertainty X Conservatives" is small and not statistically significant. 
Table1. Treatment effects on attitudes by ideology

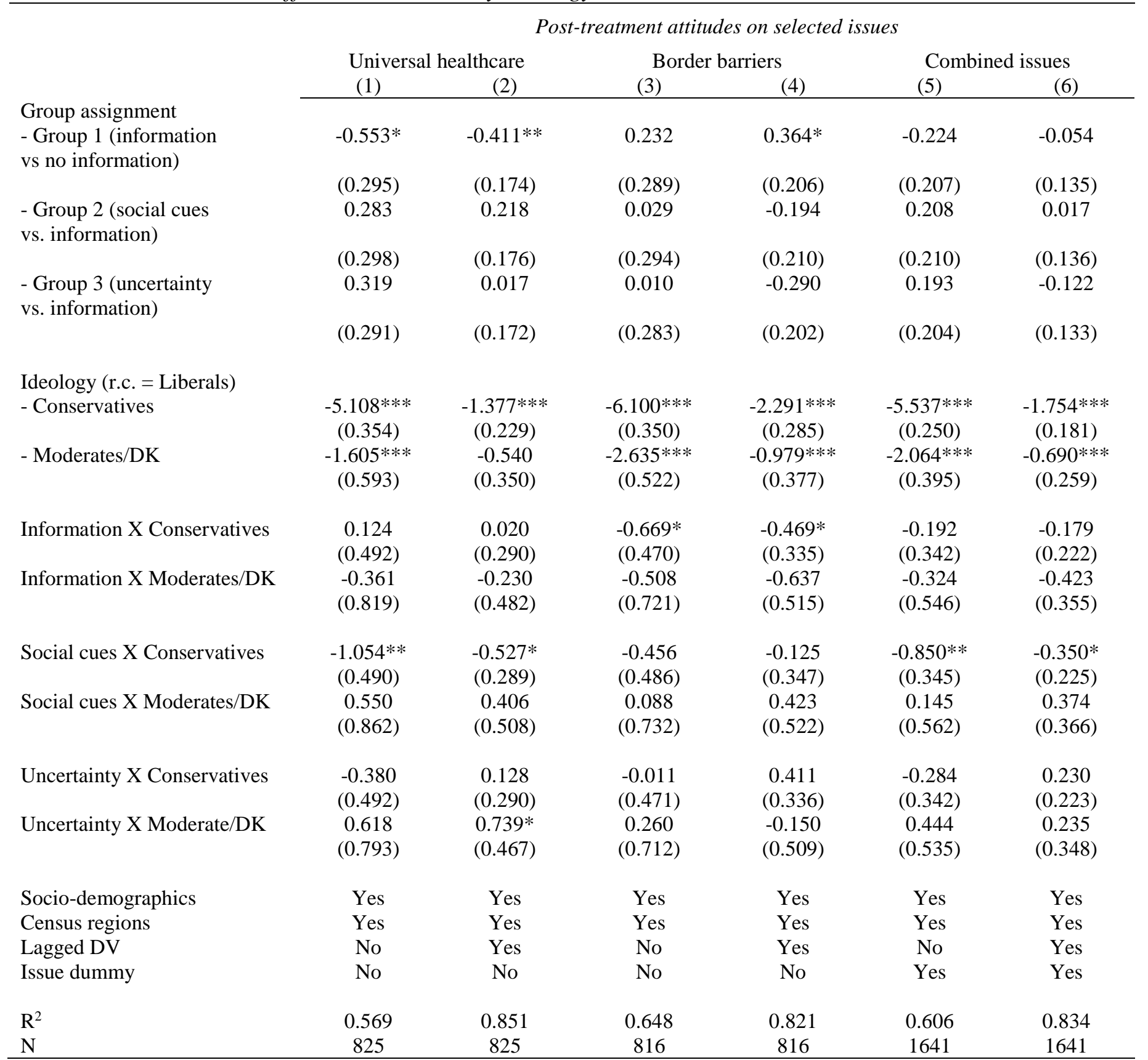

Note. OLS regression coefficients with standard errors in parentheses. Dependent variable rescaled from -5 (strongly against universal healthcare / strongly in favor of border barriers) to 5 (strongly in favor of universal healthcare / strongly against border barriers). Socio-demographics include gender, age, education level and race (White only versus other categories). $* \mathrm{p}<0.1, * * \mathrm{p}<0.05, * * * \mathrm{p}<0.01$, one-tailed

We then tested whether attitude polarization was asymmetrical. Figure 4 displays the average levels of support for the two issue proposals by ideology and treatment conditions based on regression models in Table 1. The findings reveal that most of the attitude change occurs on the 
conservative side. For one thing, we see that it was only conservatives who developed stronger (more extreme) attitudes in the presence of two-sided information, compared to the no information condition (right-hand plot). This result points to the possibility that motivated reasoning in response to counter-attitudinal information is asymmetrical even in the absence of specific relational and epistemic motives affecting information processing, above and beyond the general, directional motivation of reaching a particular conclusion.

Furthermore, Figure 4 shows that conservatives developed even stronger (more extreme) attitudes when the two-sided information was combined with social cues. The effect was larger (and statistically significant) in the case of universal healthcare (left-hand plot), but it was in the same direction in the case of border control (center plot). When both issues were combined (righthand plot), we observe that in the presence of social cues, conservatives became 6.4 percentage points (0.18 standard deviations) more extreme in their prior attitudes, compared to when social cues were not present. On the other hand, the uncertainty salience condition did not affect attitudes significantly. It is true that liberals consistently held strong attitudes in favor of universal healthcare and against border barrier expansion, and they were relatively unaffected by the presence of two-sided information, social cues, and uncertainty salience. This could be attributable to general stubbornness or, alternatively, greater experience, knowledge, and well-founded confidence in their opinions on these issues (see Baron and Jost 2019). 
Figure 4. Average attitude levels by issue, ideology, and treatment conditions

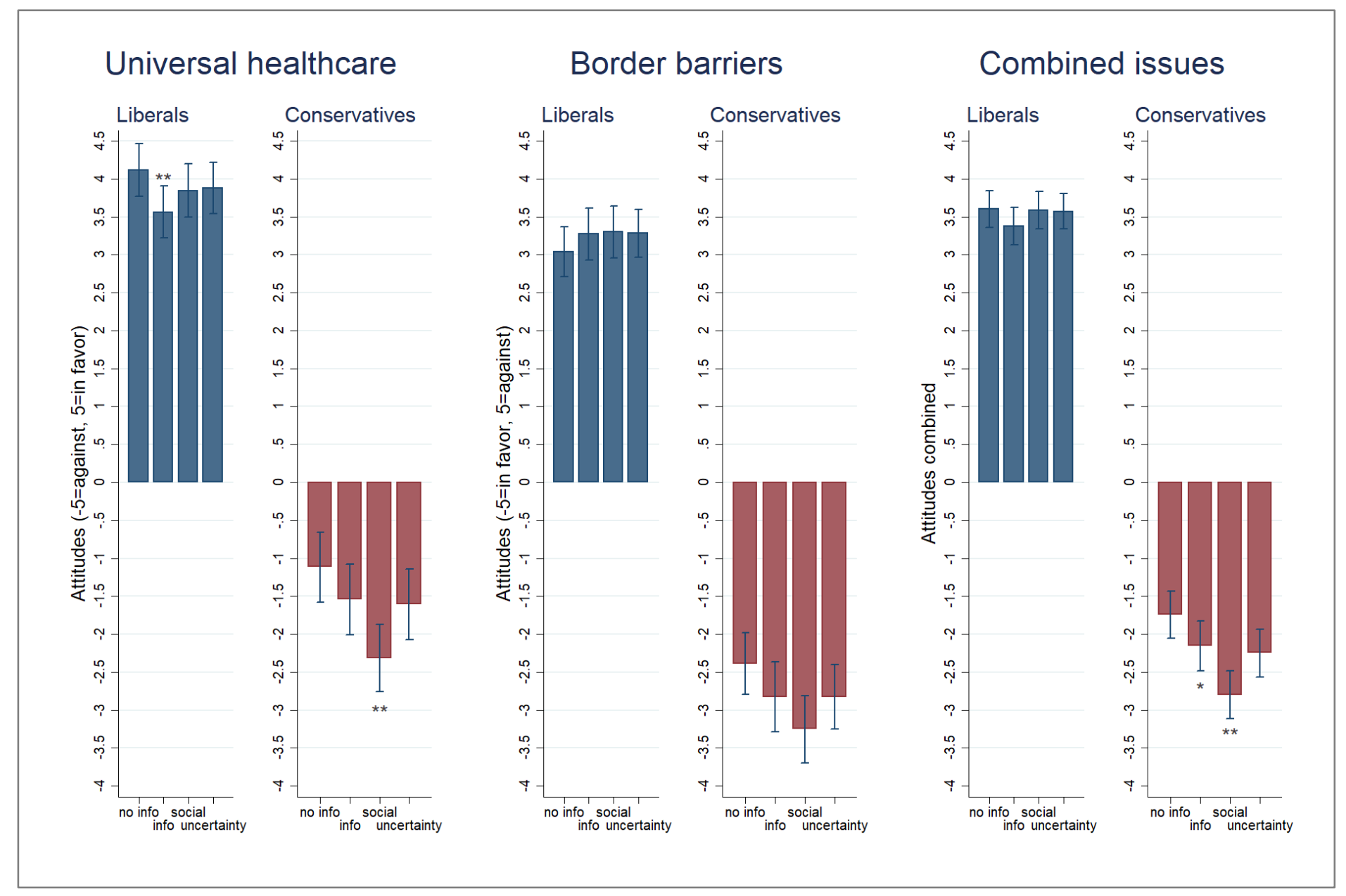

Note: Average levels based on OLS regression models in columns 1, 3 and 5 in Table 1. P-values relative to the difference between information vs. no information, and between social cues and uncertainty vs. information. $* \mathrm{p}<0.1, * * \mathrm{p}<0.05, * * * \mathrm{p}<0.01$ (one-tailed). Vertical bars are $90 \%$ confidence intervals.

These results support hypothesis H3B, which posited that the effect of social cue exposure would be stronger among conservatives than liberals. Indeed, we discovered that it was only conservatives who became more extreme in their attitudes when social cues were present. To test whether the treatment effects on attitudes were significantly larger for conservatives compared to liberals we conducted $z$ tests for the differences between coefficients (Paternoster, Brame, Mazerolle and Piquero 1998). This additional test confirmed that the effect of social cue exposure was larger among conservatives than liberals, and the difference was just around the 90\% threshold of statistical significance ( $\mathrm{p}=0.11$ and $\mathrm{p}=0.08$ depending on model specifications, see Table A8). These findings confirm that in the presence of social cues, conservatives are more likely to become 
more extreme than liberals (H3B), consistent with our expectation that ideological polarization would be asymmetrical when relational motives are activated. Because our manipulation of uncertainty salience did not influence the attitudes of our respondents significantly we were unable to corroborate the hypothesis that polarization would be symmetrical when epistemic motives are activated (H4B).

\section{Discussion}

Are there specific motives that lead individuals to become more extreme in their political attitudes after exposure to balanced (two-sided) information? Can these motives explain recent evidence that attitude polarization occurs more on the conservative than the liberal "side" (e.g., Bail et al. 2018)? We addressed these questions in a two-wave survey experiment in which we exposed participants to balanced information pertaining to two highly salient political issues: implementing universal healthcare and expanding border barriers, such as the wall between the U.S. and Mexico. In addition to providing two-sided information, we used experimental manipulations to induce two psychological mechanisms related to relational and epistemic motives that, in light of theory and research on political ideology as motivated social cognition (e.g., Jost et al. 2003, 2007, 2018), might contribute to answering these questions.

Our results suggest that relational motives to maintain homogenous social networks are highly pertinent to how people, especially political conservatives, process information and make up their minds about important social and political issues. When exposed to social cues indicating where liberals and conservatives stand on specific issues, the two groups became further apart in their attitudes. Importantly, and in line with accumulating evidence that conservatives place greater emphasis on conformity, loyalty, and group cohesion than liberals (Jost et al. 2018), we observed that, in the presence of social cues, conservatives were more likely to develop extreme attitudes than liberals, triggering asymmetric polarization. These findings show that motivated reasoning may be asymmetrical under certain conditions (Baron and Jost 2019), such as when information processing is driven by the desire to maintain social conformity. 
Contrary to our predictions, however, we did not obtain consistent evidence of increased ideological polarization when epistemic motives to reduce uncertainty were present. We induced epistemic motivation by raising the level of uncertainty concerning existing evidence pertaining to salient political issues. We observed that it was only conservatives (and not liberals) who exhibited stronger confirmation bias when uncertainty was high. That is, conservatives judged arguments supporting their pre-existing opinions to be stronger when uncertainty salience was high (vs. low). It is possible that the manipulation of epistemic motivation did not increase overall levels of ideological polarization, because liberals tended to judge arguments supporting their own preexisting opinions as the same or weaker when uncertainty salience was high (vs. low).

Another result that warrants further exploration has to do with issue heterogeneity (see also Baron and Jost 2019). Despite the fact that the experimental treatments generally exerted similar effects for the two issues under investigation, we find that conservatives changed their attitudes more on the issue of universal healthcare (than the expansion of border barriers). One possible explanation for this finding, suggested above, is that conservatives may have been less subjectively certain about their initial beliefs concerning universal healthcare than border control, and this could have led them to compensate by showing increased confirmation bias. We analyzed this possibility by inspecting responses to a question administered in the first wave of the survey in which respondents were asked how certain they were that implementing a universal healthcare system (or expanding border barriers) would benefit or damage the United States. As expected, conservatives were indeed less certain about their beliefs concerning the effectiveness of universal healthcare than border barrier expansion. Importantly, the reverse pattern held for liberals, who were less certain about their beliefs about border barriers than universal healthcare. Thus, if it is true that a lack of certainty increased confirmation bias - in direct contrast to what one would expect on the basis of Bayesian standards of rationality (see Baron and Jost 2019) — this was the case for conservative respondents but not for liberal respondents. In any case, when we included initial belief certainty as an additional interaction term in our models, we did not observe a significant interaction, indicating that the effect of social cue exposure among conservatives did not depend substantially upon initial certainty.

In conclusion, the results of our two-wave survey experiment suggest that relational motivation to maintain within-group homogeneity and conform to in-group norms plays a significant 
role in motivated reasoning, including confirmation bias and attitude polarization. Apparently because this type of relational motivation is stronger among conservatives than liberals, when people are exposed to two-sided information, conservatives exhibit more confirmation bias and attitude extremity in the presence (vs. absence) of social cues, in comparison with liberals. This is one psychological mechanism that could, at least in theory, help to explain the multiply determined phenomenon of asymmetric polarization in American politics (e.g., Grossman and Hopkins 2016).

\section{References}

Angrist, Joshua D., and Jörn-Steffen Pischke. 2009. Mostly Harmless Econometrics: An Empiricist's Companion. Princeton, NJ: Princeton University Press.

Azevedo, F., Jost, J. T., Rothmund, T., \& Sterling, J. (2019). Neoliberal Ideology and the Justification of Inequality in Capitalist Societies: Why Social and Economic Dimensions of Ideology Are Intertwined. Journal of Social Issues, 75(1), 49-88. https://doi.org/10.1111/josi.12310

Bail, Christopher A., Lisa P. Argyle, Taylor W. Brown, John P. Bumpus, Haohan Chen, M.B. Fallin Hunzaker, Jaemin Lee, Marcus Mann, Friedolin Merhout, and Alexander Volfovsky. 2018. "Exposure to Opposing Views Can Increase Political Polarization: Evidence from a Large-Scale Field Experiment on Social Media." Proceedings of the National Academy of Sciences, 1-6.

Baldassarri, Delia, and Andrew Gelman. 2008. "Partisans without Constraint: Political Polarization and Trends in American Public Opinion.” American Journal of Sociology 114 (2): 408-46.

Barberá, Pablo, John T Jost, Jonathan Nagler, Joshua A Tucker, and Richard Bonneau. 2015. "Tweeting From Left to Right: Is Online Political Communication More Than an Echo Chamber?" Psychological Science 26 (10): 1531-42.

Baron, J., \& Jost, J. T. (2019). False equivalence: Are liberals and conservatives in the U.S. equally "biased"? Perspectives on Psychological Science, 14, 292-303

Basol, M., Roozenbeek, J., \& van der Linden, S. (2020). Good news about bad news: Gamified inoculation boosts confidence and cognitive immunity against fake news. Journal of Cognition, 3(1), 2

Bayes, R., Druckman, J. N., Goods, A., \& Molden, D. C. (2020). When and How Different Motives Can Drive Motivated Political Reasoning. Political Psychology, $0(0)$. https://doi.org/10.1111/pops.12663

Benkler, Y., Faris, R., Roberts, H., \& Zuckerman, E. (2017). Study: Breitbart-led right-wing media ecosystem altered broader media agenda. Columbia Journalism Review, 3.

Bolsen, Toby, James N. Druckman, and Fay Lomax Cook. 2014. "The Influence of Partisan Motivated Reasoning on Public Opinion." Political Behavior 36 (2): 235-62.

Boutyline, Andrei, and Robb Willer. 2017. "The Social Structure of Political Echo Chambers: Variation in Ideological Homophily in Online Networks.” Political Psychology 38 (3): 551-69. 
Brader, T., De Sio, L., Paparo, A., \& Tucker, J. A. (2020). "Where You Lead, I Will Follow”: Partisan Cueing on High-Salience Issues in a Turbulent Multiparty System. Political Psychology, 41(4), 795-812.

Bullock, John G. 2009. "Partisan Bias and the Bayesian Ideal in the Study of Public Opinion." The Journal of Politics 71 (3): 1109-24.

Carmines, E. G., Ensley, M. J., \& Wagner, M. W. (2012). Political ideology in American politics: One, two, or none? The Forum, 10(3).

Chambers, Simone. 2003. "Deliberative Democratic Theory." Annual Review of Political Science 6 (1): 307-26.

Coan, T. G., Merolla, J. L., Stephenson, L. B., \& Zechmeister, E. J. (2008). It's not easy being green: Minor party labels as heuristic aids. Political Psychology, 29(3), 389-405.

Collins, Timothy P., Jarret T. Crawford, and Mark J. Brandt. 2017. "No Evidence for Ideological Asymmetry in Dissonance Avoidance: Unsuccessful Close and Conceptual Replications of Nam, Jost, and van Bavel (2013)." Social Psychology 48 (3): 123-34.

Conroy-Krutz, Jeffrey, and Devra C. Moehler. 2015. "Moderation from Bias: A Field Experiment on Partisan Media in a New Democracy." The Journal of Politics 77 (2): 575-87.

Dickson, E. S., \& Scheve, K. (2006). Social identity, political speech, and electoral competition. Journal of Theoretical Politics, 18(1), 5-39.

Druckman, J. N., Peterson, E., \& Slothuus, R. (2013). "How Elite Partisan Polarization Affects Public Opinion Formation." American Political Science Review, 107(1), 57-79.

Druckman, James N., and Toby Bolsen. 2011. "Framing, Motivated Reasoning, and Opinions About Emergent Technologies." Journal of Communication 61: 659-88.

Druckman, James N., Donald P. Green, James H. Kuklinski, and Arthur Lupia. 2011. "Experiments: An Introduction to Core Concepts." In Cambridge Handbook of Experimental Political Science, edited by James N. Druckman, Donald P. Green, James H. Kuklinski, and Arthur Lupia, 1-1003. New York: Cambridge University Press.

Druckman, James N., Jordan Fein, and Thomas J. Leeper. 2012. "A Source of Bias in Public Opinion Stability.” American Political Science Review 106 (02): 430-54.

Frimer, Jeremy A., Linda J. Skitka, and Matt Motyl. 2017. "Liberals and Conservatives Are Similarly Motivated to Avoid Exposure to One Another's Opinions.” Journal of Experimental Social Psychology 72: $1-12$.

Garrett, R Kelly. 2009. "Echo Chambers Online?: Politically Motivated Selective Exposure among Internet News Users." Journal of Computer-Mediated Communication 14 (2): 265-85.

Gerber, Alan S., Donald P. Green, and Ron Shachar. 2003. "Voting May Be Habit-Forming: Evidence from a Randomized Field Experiment.” American Journal of Political Science 47 (3): 540-50.

Grinberg, Nir, Kenneth Joseph, Lisa Friedland, Briony Swire-thompson, and David Lazer. 2019. "Fake News on Twitter during the 2016 U.S. Presidential Election.” Science 378 (January): 374-78.

Guess, A., Nagler, J., \& Tucker, J. (2019). Less than you think: Prevalence and predictors of fake news dissemination on Facebook. Science Advances, 5(1), eaau4586. 
Guess, A., Nyhan, B., \& Reifler, J. (2020). Exposure to untrustworthy websites in the 2016 U.S. election. Nature Human Behaviour, 4(5), 472-480. https://doi.org/10.1038/s4156 2-020-0833-X

Guess, Andrew, and Alexander Coppock. 2018. "Does Counter-Attitudinal Information Cause Backlash? Results from Three Large Survey Experiments.” British Journal of Political Science, 1-19.

Hart, W., Albarracín, D., Eagly, A. H., Brechan, I., Lindberg, M. J., \& Merrill, L. (2009). Feeling validated versus being correct: A meta-analysis of selective exposure to information. Psychological Bulletin, 135(4), 555-588.

Hetherington, Marc J. 2001. "Resurgent Mass Partisanship: The Role of Elite Polarization.” American Political Science Review 95 (3): 619-31.

Hibbing, John R., Kevin B. Smith, and John R. Alford. 2014. Predisposed: Liberals, Conservatives, and the Biology of Political Differences. New York: Routledge.

Hill, Seth J. 2017. "Learning Together Slowly: Bayesian Updating About Political Facts.” Journal of Politics 79 (4): 1403-18.

Hjorth, Frederik, \& Adler-Nissen, R Rebecca (2019). Ideological asymmetry in the reach of pro-Russian digital disinformation to United States audiences. Journal of Communication, 69(2), 168-192.

Hobolt, S. B., Leeper, T. J., \& Tilley, J. (2020). Divided by the Vote: Affective Polarization in the Wake of the Brexit Referendum. British Journal of Political Science, 1-18.

Iyengar, S., Lelkes, Y., Levendusky, M., Malhotra, N., \& Westwood, S. J. (2019). The Origins and Consequences of Affective Polarization in the United States. Annual Review of Political Science, 22(1), $129-146$.

Iyengar, Shanto, and Kyu S. Hahn. 2009. "Red Media, Blue Media: Evidence of Ideological Selectivity in Media Use.” Journal of Communication 59 (1): 19-39.

Iyengar, Shanto, and Sean J. Westwood. 2015. "Fear and Loathing across Party Lines: New Evidence on Group Polarization.” American Journal of Political Science 59 (3): 690-707.

Iyengar, Shanto, Kyu S. Hahn, Jon A. Krosnick, and John Walker. 2008. "Selective Exposure to Campaign Communication: The Role of Anticipated Agreement and Issue Public Membership." Journal of Politics 70 (1): 186-200.

Jost, J. T., Ledgerwood, A., \& Hardin, C. D. (2008). Shared reality, system justification, and the relational basis of ideological beliefs. Social and Personality Psychology Compass, 2(1), 171-186. https://doi.org/10.1111/j.1751-9004.2007.00056.x

Jost, John T. 2017. "Ideological Asymmetries and the Essence of Political Psychology." Political Psychology 38 (2): 167-208.

Jost, John T., and David M. Amodio. 2012. "Political Ideology as Motivated Social Cognition: Behavioral and Neuroscientific Evidence." Motivation and Emotion 36 (1): 55-64.

Jost, John T., Erin P. Hennes, and Howard Lavine. 2013. "'Hot' Political Cognition: Its Self-, Group-, and System-Serving Purposes.” In Oxford Handbook of Social Cognition, edited by D. E. Carlson, 85175. New York: Oxford University Press.

Jost, John T., Jack Glaser, Arie W. Kruglanski, and Frank J. Sulloway. 2003. "Political Conservatism as Motivated Social Cognition.” Psychological Bulletin 129 (3): 339-75. 
Jost, John T., Jaime L. Napier, Hulda Thorisdottir, Samuel D. Gosling, Tibor P. Palfai, and Brian Ostafin. 2007. "Are Needs to Manage Uncertainty and Threat Associated With Political Conservatism or Ideological Extremity?” Personality \& Social Psychology Bulletin 33 (7): 989-1007.

Jost, John T., Sander van der Linden, Costas Panagopoulos, and Curtis D. Hardin. 2018. "Ideological Asymmetries in Conformity, Desire for Shared Reality, and the Spread of Misinformation." Current Opinion in Psychology 23. Elsevier Ltd: 77-83.

Kahan, Dan M. 2013. "Ideology, Motivated Reasoning, and Cognitive Reflection: An Experimental Study." Judgment \& Decision Making 8 (4): 407-24.

Kahan, Dan M. 2015. "The Politically Motivated Reasoning Paradigm, Part 1: What Politically Motivated Reasoning Is and How to Measure It." In Emerging Trends in the Social and Behavioral Sciences, John Wiley \& Sons, Inc.

Kam, C. D. (2005). Who toes the party line? Cues, values, and individual differences. Political Behavior, 27(2), 163-182.

Kam, Cindy D., and Marc J. Trussler. 2017. "At the Nexus of Observational and Experimental Research: Theory, Specification, and Analysis of Experiments with Heterogeneous Treatment Effects." Political Behavior 39 (4).

Keele, Luke, \& Kelly, Nathan J. (2006). "Dynamic models for dynamic theories: The ins and outs of lagged dependent variables." Political Analysis 14, 186-205

Knobloch-Westerwick, S., Mothes, C., Johnson, B. K., Westerwick, A., \& Donsbach, W. 2015. "Political Online Information Searching in Germany and the United States: Confirmation Bias, Source Credibility, and Attitude Impacts." Journal of Communication 65(3): 489-511.

Knobloch-Westerwick, Silvia. 2012. "Selective Exposure and Reinforcement of Attitudes and Partisanship Before a Presidential Election.” Journal of Communication 62 (4): 628-42.

Kunda, Ziva. 1990. “The Case for Motivated Reasoning.” Psychological Bulletin 108 (3): 480-98.

Leeper, Thomas J. 2014. “The Informational Basis for Mass Polarization.” Public Opinion Quarterly 78 (1): $27-46$.

Leeper, Thomas J., and Rune Slothuus. 2014. "Political Parties, Motivated Reasoning, and Public Opinion Formation." Advances in Political Psychology 35 (Suppl. 1): 129-56.

Levendusky, Matthew S. 2013. "Why Do Partisan Media Polarize Viewers?” American Journal of Political Science 57 (3): 611-23.

Lodge, Milton, and Charles S Taber. 2013. The Rationalizing Voter. Cambridge; New York: Cambridge University Press.

Lord, C. G., Ross, L., \& Lepper, M. R. (1979). Biased assimilation and attitude polarization: The effects of prior theories on subsequently considered evidence. Journal of Personality and Social Psychology, 37(11), 2098-2109.

Miller, Andrea L., Margarita Krochik, and John T. Jost. 2009. "Political Ideology and Persuasion: Systematic and Heuristic Processing among Liberals and Conservatives." Yale Review of Undergraduate Research in Psychology 1: 14-28. 
Morton, R., and K. C. Williams. 2010. Experimental Political Science and the Study of Causality: From Nature to the Lab. New York: Cambridge University Press.

Moy, P., \& Rinke, E. M. (2012). Attitudinal and Behavioral Consequences of Published Opinion Polls. In J. Strömbäck \& C. Holtz-Bacha (Eds.), Opinion Polls and the Media: Reflecting and Shaping Public Opinion (pp. 225-245). Basinstoke, UK: Palgrave Macmillan.

Mutz, Diana C. 2006. Hearing the Other Side: Deliberative versus Participatory Democracy. New York: Cambridge University Press.

Nickerson, Raymond S. 1998. "Confirmation Bias: A Ubiquitous Phenomenon in Many Guises.” Review of General Psychology 2 (2): 175-220.

Nir, L. (2011). Motivated reasoning and public opinion perception. Public Opinion Quarterly, 75(3), 504532. https://doi.org/10.1093/poq/nfq076

Oakes, Michael J., and Henry A. Feldman. 2001. "Statistical Power for Nonequivalent Pretest-Posttest Designs.” Evaluation Review 25 (1): 3-28.

Paternoster, R., Brame, R., Mazerolle, P., and Piquero, A. (1998). "Using the correct statistical test for the equality of regression coefficients." Criminology, 36(4): 859-866. doi:10.1111/j.17459125.1998.tb01268.x

Petersen, Michael Bang, Martin Skov, Søren Serritzlew, and Thomas Ramsøy. 2013. "Motivated Reasoning and Political Parties: Evidence for Increased Processing in the Face of Party Cues." Political Behavior 35 (4): 831-54.

Pew Research Center. (2012, August 24). Political party quiz: How we placed you. Retrieved from http://www.people-press.org/2012/08/24/political-party-quiz-how-we-placed-you

Redlawsk, D. P. (2002). Hot Cognition or Cool Consideration? Testing the Effects of Motivated Reasoning on Political Decision Making. The Journal of Politics, 64(4), 1021-1044.

Schwartz, Shalom H., Gian Vittorio Caprara, and Michele Vecchione. 2010. "Basic Personal Values, Core Political Values, and Voting: A Longitudinal Analysis.” Political Psychology 31 (3): 421-52.

Taber, C. S., \& Lodge, M. (2016). The Illusion of Choice in Democratic Politics: The Unconscious Impact of Motivated Political Reasoning. Advances in Political Psychology, 37(Suppl. 1), 61-85.

Taber, C. S., Cann, D., \& Kucsova, S. (2009). The Motivated Processing of Political Arguments. Political Behavior, 31, 137-155.

Taber, Charles S, and Milton Lodge. 2006. "Motivated Skepticism in the Evaluation of Political Beliefs." American Journal of Political Science 50 (3): 755-69.

Taber, Charles S, and Milton Lodge. 2016. "The Illusion of Choice in Democratic Politics: The Unconscious Impact of Motivated Political Reasoning." Advances in Political Psychology 37 (Suppl. 1): $61-85$.

Taber, Charles S., Damon Cann, and Simona Kucsova. 2009. "The Motivated Processing of Political Arguments." Political Behavior 31: 137-55.

van der Linden, S., Panagopoulos, C., Azevedo, F., \& Jost, J. T. (2020). The Paranoid Style in American Politics Revisited: An Ideological Asymmetry in Conspiratorial Thinking. Political Psychology, 0(0), 1-29. https://doi.org/10.1111/pops.12681 
Wood, Thomas, and Ethan Porter. 2018. “The Elusive Backfire Effect: Mass Attitudes' Steadfast Factual Adherence." Political Behavior. Springer US, 1-29.

Zell, E., \& Bernstein, M. J. (2014). You May Think You're Right... Young Adults Are More Liberal Than They Realize. Social Psychological and Personality Science, 5(3), 326-333. 


\section{Appendix A. Additional analyses and robustness checks}

Table A1. Correlations between failing quality checks and group assignment

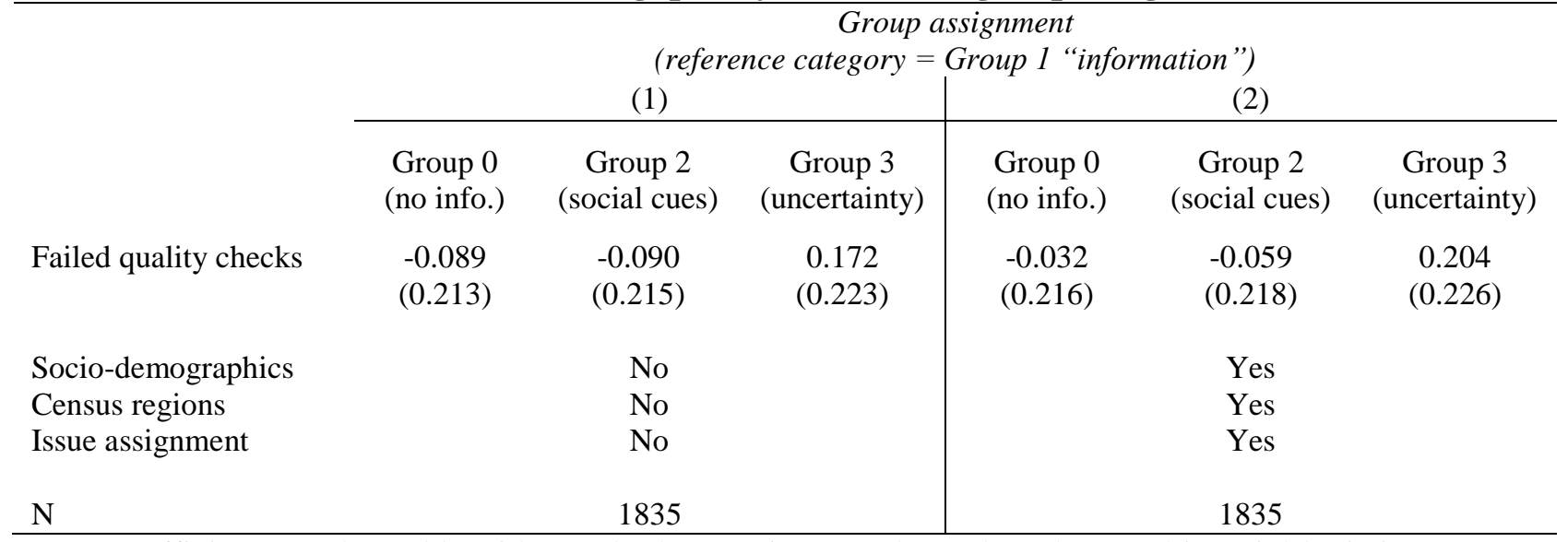

Note: Coefficients are log odds with standard errors in parentheses based on multinomial logistic regressions of random assignment to groups. Socio-demographics include gender, age, education level, and race (White only versus other categories). 
Table A2. Summary statistics

Universal healthcare prior attitudes (W1)

Border control prior attitudes (W1)

Healthcare posterior attitudes (W2)

Border control posterior attitudes (W2)

Self-reported ideology: liberals

Self-reported ideology: conservatives

Self-reported ideology: moderates/DK

Operational ideology: liberals

Operational ideology: conservatives

Operational ideology: libertarians

Operational ideology: communitarians

Female

1641

0.34

1641

1641

1641

0.41

0.12

0.57

0.33

0.10

1641

0.12

SD

Min

Max

3.35

3.35
3.55

10

4.43

3.55

0

10

Age

1641

Education: high school diploma or below

1641

3.42

3.55

10

6.93

10

Education: some college (no degree)

1641

0.49

0.47

0.30

0

0

Education: bachelor's degree

1641

0.48

0.49

0.32

0.33

$\begin{array}{ll}0 & 1 \\ 0 & 1 \\ 0 & 1\end{array}$

Education: advanced degree

1641

0.50

$\begin{array}{ll}0 & 1 \\ 0 & 1 \\ 0 & 1 \\ 0 & 1\end{array}$

Race: "not White" (vs. White only)

1641

Census area: Midwest

1641

1641

1641

12.76

0

1

Census area: Northeast

Census area: South

Census area: West

Group 0 (no info, healthcare, $N=206$ )

Group 0 (no info, border barriers, $\mathrm{N}=214$ )

Group 1 (info, healthcare, $\mathrm{N}=204$ )

Group 1 (info, border barriers, $\mathrm{N}=187$ )

Group 2 (social cues, healthcare, $\mathrm{N}=202$ )

Group 2 (social cues, border barriers, N=194)

Group 3 (uncertainty, healthcare, $N=2013$ )

Group 3 (uncertainty, border barriers, $N=221$ )

1641

1641

1641

1641

1641

1641

1641

1641
0.12

0.32

0.39

0.17

0.19

0.22

0.18

0.39

0.21

0.32

0.47

0.49

0.38

0.39

0.41

0.39

0.49

0.40

0.13

0.13

0.12

0.11

0.12

0.12

0.13

0.13

\subsection{3}

0.34

0.33

0.32

0.33

0.32

0.34

0.34

17

79

$\begin{array}{ll}0 & 1 \\ 0 & 1 \\ 0 & 1 \\ 0 & 1\end{array}$

$0 \quad 1$

$\begin{array}{ll}0 & 1 \\ 0 & 1 \\ 0 & 1 \\ 0 & 1\end{array}$

\begin{tabular}{ll}
0 & 1 \\
0 & 1 \\
0 & 1 \\
0 & 1 \\
0 & 1 \\
0 & 1 \\
0 & 1 \\
0 & 1 \\
\hline
\end{tabular}




\begin{tabular}{|c|c|c|c|c|c|c|}
\hline \multirow{2}{*}{ Ideology (r.c. = Liberals) } & \multicolumn{6}{|c|}{$\begin{array}{c}\text { Group assignment } \\
\text { (baseline category }=\text { Group 1, information) }\end{array}$} \\
\hline & \multicolumn{2}{|c|}{$\begin{array}{l}\text { Group } 0 \\
\text { (no info) }\end{array}$} & \multicolumn{2}{|c|}{$\begin{array}{c}\text { Group } 2 \\
\text { (social cues) }\end{array}$} & \multicolumn{2}{|c|}{$\begin{array}{c}\text { Group } 3 \\
\text { (uncertainty) }\end{array}$} \\
\hline $\begin{array}{l}\text { - Conservatives } \\
\text { - Moderates/DK }\end{array}$ & $\begin{array}{l}0.111 \\
0.041\end{array}$ & $\begin{array}{l}(0.161) \\
(0.248)\end{array}$ & $\begin{array}{c}0.123 \\
-0.026\end{array}$ & $\begin{array}{l}(0.163) \\
(0.255)\end{array}$ & $\begin{array}{c}-0.038 \\
0.090\end{array}$ & $\begin{array}{l}(0.161) \\
(0.242)\end{array}$ \\
\hline Female & $-0.270 *$ & $(0.144)$ & -0.162 & $(0.146)$ & -0.147 & $(0.143)$ \\
\hline Age & -0.008 & $(0.006)$ & -0.003 & $(0.006)$ & -0.004 & $(0.006)$ \\
\hline $\begin{array}{l}\text { Education (r.c.=some college) } \\
\text { - High school diploma or below } \\
\text { - Bachelor's degree } \\
\text { - Advanced degree }\end{array}$ & $\begin{array}{c}-0.212 \\
-0.212 \\
0.001\end{array}$ & $\begin{array}{l}(0.243) \\
(0.168) \\
(0.216)\end{array}$ & $\begin{array}{c}-0.115 \\
-0.236 \\
0.084\end{array}$ & $\begin{array}{l}(0.244) \\
(0.171) \\
(0.216)\end{array}$ & $\begin{array}{c}-0.016 \\
-0.059 \\
0.058\end{array}$ & $\begin{array}{l}(0.239) \\
(0.167) \\
(0.216)\end{array}$ \\
\hline Race "not White" (vs. White) & -0.171 & $(0.189)$ & 0.079 & $(0.187)$ & -0.199 & $(0.189)$ \\
\hline $\begin{array}{l}\text { Census area (r.c.=South) } \\
\text { - Midwest } \\
\text { - Northeast } \\
\text { - West }\end{array}$ & $\begin{array}{l}0.019 \\
0.281 \\
0.242\end{array}$ & $\begin{array}{l}(0.193) \\
(0.197) \\
(0.195)\end{array}$ & $\begin{array}{l}0.229 \\
0.227 \\
0.302\end{array}$ & $\begin{array}{l}(0.192) \\
(0.204) \\
(0.198)\end{array}$ & $\begin{array}{c}0.195 \\
-0.004 \\
0.252\end{array}$ & $\begin{array}{l}(0.185) \\
(0.204) \\
(0.192)\end{array}$ \\
\hline $\begin{array}{l}\text { Issue assignment (border barriers } \\
\text { vs. universal healthcare) }\end{array}$ & 0.121 & $(0.141)$ & 0.047 & $(0.143)$ & 0.123 & $(0.140)$ \\
\hline Constant & 0.450 & $(0.283)$ & 0.075 & $(0.289)$ & 0.230 & $(0.282)$ \\
\hline $\begin{array}{l}\text { Pseudo } \mathrm{R}^{2} \\
\mathrm{~N}\end{array}$ & & & $\begin{array}{l}.0 \\
16\end{array}$ & & & \\
\hline
\end{tabular}

Note: Coefficients are log odds with standard errors in parentheses based on multinomial logistic regressions of random assignment to groups. ${ }^{*} \mathrm{p}<.1, * * \mathrm{p}<.05, * * * \mathrm{p}<.01$ 
Table A4. Issue relevance and prior attitudes (Wave 1)

\begin{tabular}{|c|c|c|c|c|c|c|c|c|}
\hline \multirow{2}{*}{ Ideology (r.c. = Liberals) } & \multicolumn{4}{|c|}{ Issue relevance (0-10) } & \multicolumn{4}{|c|}{ Prior attitudes $(0-10)$} \\
\hline & \multicolumn{2}{|c|}{$\begin{array}{l}\text { Universal } \\
\text { healthcare } \\
\text { (1) }\end{array}$} & \multicolumn{2}{|c|}{$\begin{array}{l}\text { Border } \\
\text { control } \\
\text { (2) }\end{array}$} & \multicolumn{2}{|c|}{$\begin{array}{c}\text { Universal } \\
\text { healthcare } \\
\text { (3) }\end{array}$} & \multicolumn{2}{|c|}{$\begin{array}{l}\text { Border } \\
\text { barriers } \\
\text { (4) }\end{array}$} \\
\hline $\begin{array}{l}\text { - Conservatives } \\
\text { - Moderates/DK }\end{array}$ & $\begin{array}{l}-2.855 * * * \\
-0.844 * * *\end{array}$ & $\begin{array}{l}(0.177) \\
(0.282)\end{array}$ & $\begin{array}{c}3.101 * * * * \\
0.028\end{array}$ & $\begin{array}{l}(0.233) \\
(0.346)\end{array}$ & $\begin{array}{l}-5.136 * * * \\
-1.308 * * *\end{array}$ & $\begin{array}{l}(0.185) \\
(0.296)\end{array}$ & $\begin{array}{l}5.844^{* * * *} \\
2.466^{* * * *}\end{array}$ & $\begin{array}{l}(0.179) \\
(0.263)\end{array}$ \\
\hline Female & $0.424 * * *$ & $(0.158)$ & $0.632^{* * * *}$ & $(0.208)$ & 0.039 & $(0.166)$ & $-0.337 * *$ & $(0.159)$ \\
\hline Age & 0.006 & $(0.006)$ & 0.005 & $(0.008)$ & $-0.013 * *$ & $(0.007)$ & $0.021 * * *$ & $(0.006)$ \\
\hline $\begin{array}{l}\text { Education (r.c.=some college) } \\
\text { - High school or below } \\
\text { - Bachelor's degree } \\
\text { - Advanced degree }\end{array}$ & $\begin{array}{c}0.010 \\
-0.017 \\
0.170\end{array}$ & $\begin{array}{l}(0.267) \\
(0.186) \\
(0.232)\end{array}$ & $\begin{array}{l}0.349 \\
0.075 \\
0.238\end{array}$ & $\begin{array}{l}(0.348) \\
(0.243) \\
(0.312)\end{array}$ & $\begin{array}{c}-0.180 \\
-0.332^{*} \\
-0.347\end{array}$ & $\begin{array}{l}(0.279) \\
(0.195) \\
(0.244)\end{array}$ & $\begin{array}{c}0.088 \\
-0.465 * * \\
-0.625 * *\end{array}$ & $\begin{array}{l}(0.266) \\
(0.186) \\
(0.239)\end{array}$ \\
\hline Race "not White" (vs. White) & -0.058 & $(0.206)$ & $0.515^{*}$ & $(0.276)$ & -0.026 & $(0.217)$ & $0.498 * *$ & $(0.212)$ \\
\hline $\begin{array}{l}\text { Census area (r.c.=South) } \\
\text { - Midwest } \\
\text { - Northeast } \\
\text { - West }\end{array}$ & $\begin{array}{c}-0.152 \\
0.197 \\
-0.244\end{array}$ & $\begin{array}{l}(0.207) \\
(0.224) \\
(0.214)\end{array}$ & $\begin{array}{c}0.039 \\
0.289 \\
-0.280\end{array}$ & $\begin{array}{l}(0.278) \\
(0.287) \\
(0.275)\end{array}$ & $\begin{array}{l}-0.121 \\
0.159 \\
0.007\end{array}$ & $\begin{array}{l}(0.216) \\
(0.235) \\
(0.225)\end{array}$ & $\begin{array}{c}0.091 \\
0.395^{*} \\
-0.446^{* *}\end{array}$ & $\begin{array}{l}(0.213) \\
(0.219) \\
(0.211)\end{array}$ \\
\hline Constant & $8.181 * * *$ & $(0.309)$ & 3.648 *** & $(0.397)$ & $9.720 * * *$ & $(0.323)$ & $1.845^{* * * *}$ & $(0.303)$ \\
\hline $\begin{array}{l}\mathrm{R}^{2} \\
\mathrm{~N}\end{array}$ & $\begin{array}{l}.26 \\
82\end{array}$ & & & & $\begin{array}{l}.5 \\
82\end{array}$ & & $\begin{array}{l}.6 \\
8\end{array}$ & \\
\hline
\end{tabular}

Note: OLS Regression coefficients with standard errors in parentheses. Data from Wave 1. Issue relevance: values from 0 (not at all relevant) to 10 (absolutely relevant). Prior attitudes: values from 0 (strongly against) to 10 (strongly in favor). * $\mathrm{p}<.1, * * \mathrm{p}<.05, * * * \mathrm{p}<.01$ 
Table A5. Confirmation bias

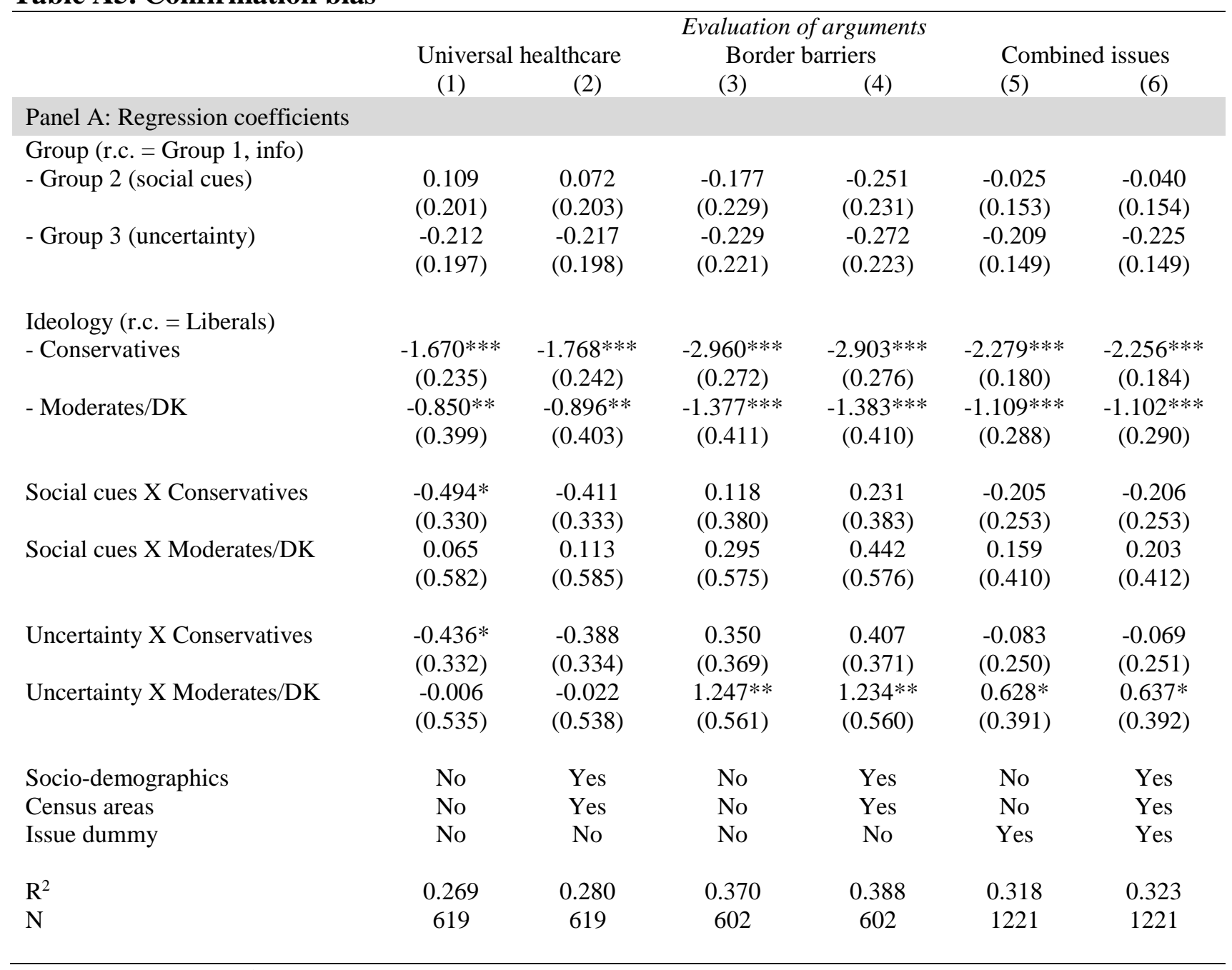

(continues on next page) 
(Table A5 continues)

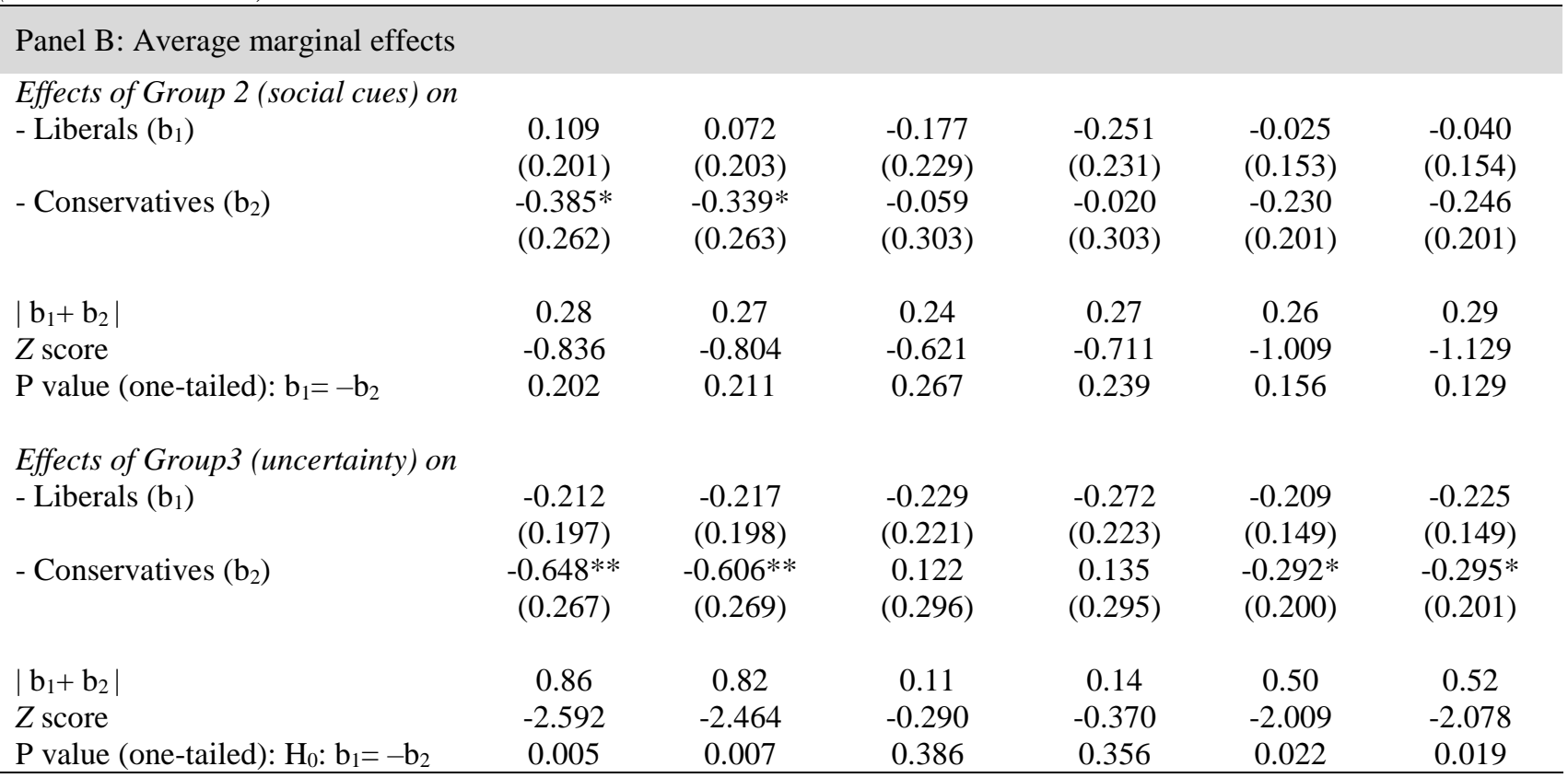

Note: Panel A: OLS regression coefficients with standard errors in parentheses. Evaluation of arguments: values ranging from -5 to 5 ; positive values indicate stronger evaluation of pro universal healthcare/anti border barriers arguments versus relative counterarguments, and vice versa for negative values. Socio-demographics: gender, age, education level, race (White-only vs. others).

Panel B: Average marginal effects of treatments within ideology categories. Formula for $Z$ score from Paternoster, Brame, Mazerolle and Piquero (1998).

$* \mathrm{p}<.1, * * \mathrm{p}<.05, * * * \mathrm{p}<.01$ (one-tailed for interaction coefficients and Panel B) 
Table A6. Confirmation bias (alternative measure of ideology)

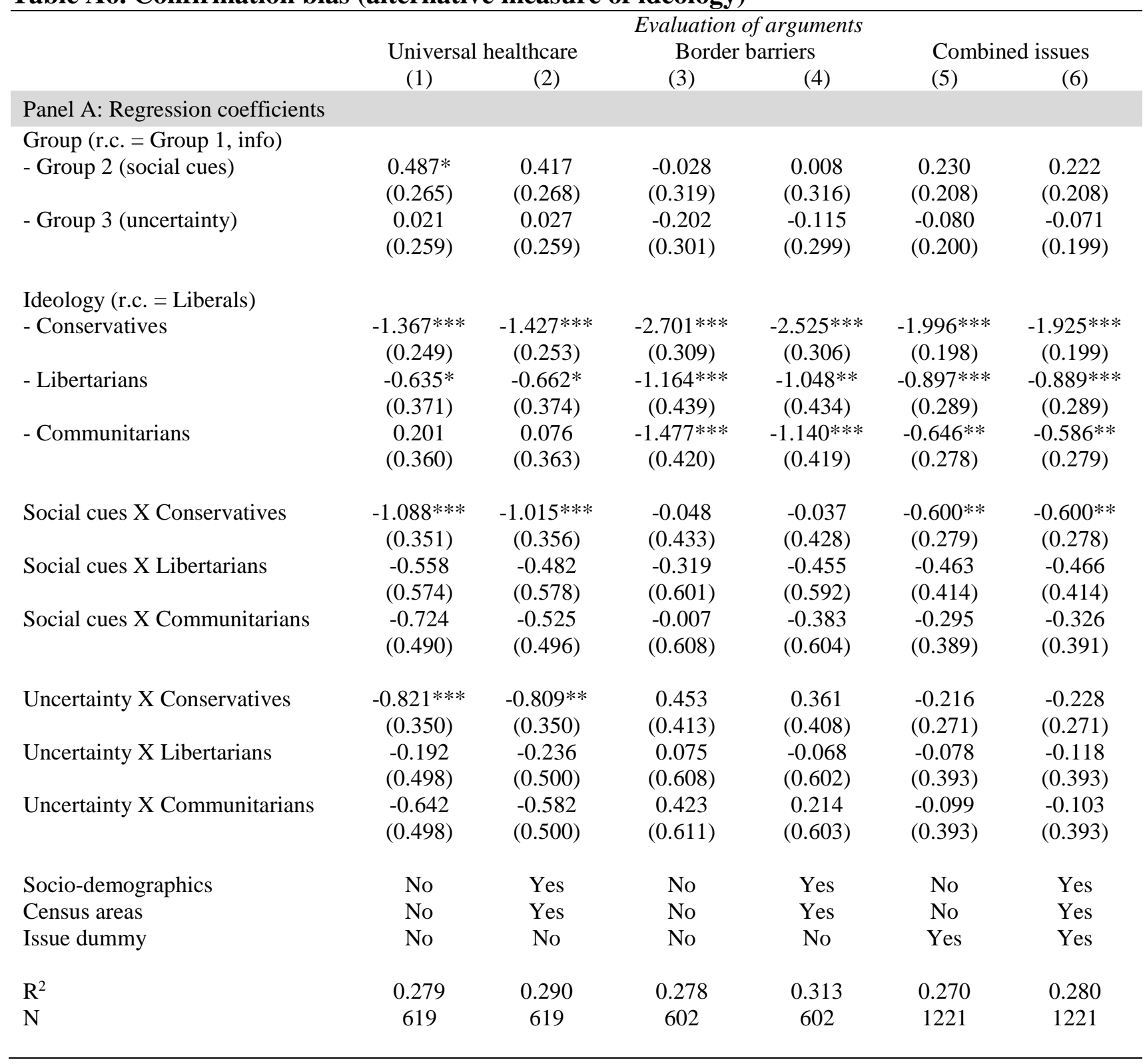

(continue on next page) 
(Table A6 continues)

\begin{tabular}{|c|c|c|c|c|c|c|}
\hline \multicolumn{7}{|l|}{ Panel B: Average marginal effects } \\
\hline $\begin{array}{l}\text { Effects of Group } 2 \text { (social cues) on } \\
\text { - Liberals }\left(\mathrm{b}_{1}\right)\end{array}$ & $\begin{array}{c}0.487^{* *} \\
(0.265)\end{array}$ & $\begin{array}{l}0.417^{*} \\
(0.268)\end{array}$ & $\begin{array}{l}-0.028 \\
(0.319)\end{array}$ & $\begin{array}{c}0.008 \\
(0.316)\end{array}$ & $\begin{array}{c}0.230 \\
(0.208)\end{array}$ & $\begin{array}{c}0.222 \\
(0.208)\end{array}$ \\
\hline - Conservatives $\left(\mathrm{b}_{2}\right)$ & $\begin{array}{c}-0.601 * * * \\
(0.230)\end{array}$ & $\begin{array}{c}-0.598^{* * *} \\
(0.233)\end{array}$ & $\begin{array}{l}-0.076 \\
(0.294)\end{array}$ & $\begin{array}{l}-0.029 \\
(0.291)\end{array}$ & $\begin{array}{c}-0.370^{* * *} \\
(0.186)\end{array}$ & $\begin{array}{c}-0.378 * * \\
(0.186)\end{array}$ \\
\hline $\begin{array}{l}\left|\mathrm{b}_{1}+\mathrm{b}_{2}\right| \\
Z \text { score } \\
\mathrm{P} \text { value (one-tailed): } \mathrm{b}_{1}=-\mathrm{b}_{2}\end{array}$ & $\begin{array}{c}0.11 \\
-0.325 \\
0.373\end{array}$ & $\begin{array}{c}0.18 \\
-0.510 \\
0.305\end{array}$ & $\begin{array}{c}0.10 \\
-0.240 \\
0.405\end{array}$ & $\begin{array}{c}0.02 \\
-0.049 \\
0.480\end{array}$ & $\begin{array}{c}0.14 \\
-0.502 \\
0.308\end{array}$ & $\begin{array}{c}0.16 \\
-0.559 \\
0.288\end{array}$ \\
\hline \multicolumn{7}{|l|}{ Effects of Group3 (uncertainty) on } \\
\hline - Liberals $\left(\mathrm{b}_{1}\right)$ & $\begin{array}{c}0.021 \\
(0.259)\end{array}$ & $\begin{array}{c}0.027 \\
(0.259)\end{array}$ & $\begin{array}{l}-0.202 \\
(0.301)\end{array}$ & $\begin{array}{l}-0.115 \\
(0.299)\end{array}$ & $\begin{array}{l}-0.080 \\
(0.200)\end{array}$ & $\begin{array}{l}-0.071 \\
(0.199)\end{array}$ \\
\hline - Conservatives $\left(\mathrm{b}_{2}\right)$ & $\begin{array}{c}-0.801 * * * \\
(0.235)\end{array}$ & $\begin{array}{c}-0.783 * * * \\
(0.236)\end{array}$ & $\begin{array}{c}0.251 \\
(0.282)\end{array}$ & $\begin{array}{c}0.247 \\
(0.277)\end{array}$ & $\begin{array}{l}-0.296^{*} \\
(0.183)\end{array}$ & $\begin{array}{l}-0.298^{*} \\
(0.183)\end{array}$ \\
\hline$\left|b_{1}+b_{2}\right|$ & 0.78 & 0.76 & 0.05 & 0.13 & 0.38 & 0.37 \\
\hline$Z$ score & -2.230 & -2.158 & 0.119 & 0.324 & -1.387 & -1.365 \\
\hline$P$ value (one-tailed): $\mathrm{H}_{0}: \mathrm{b}_{1}=-\mathrm{b}_{2}$ & 0.013 & 0.015 & 0.453 & 0.373 & 0.083 & 0.086 \\
\hline
\end{tabular}

Note: See Table A5. Measure of ideology based on six attitude questions on social and economic issues in Appendix B. 
Table A7. Average treatment effects on attitudes

\begin{tabular}{|c|c|c|c|c|c|c|}
\hline & \multicolumn{6}{|c|}{ Post-treatment attitudes on selected issues } \\
\hline & \multirow{2}{*}{\multicolumn{2}{|c|}{$\begin{array}{l}\text { Universal healthcare } \\
\text { (1) }\end{array}$}} & \multicolumn{2}{|c|}{ Border barriers } & \multicolumn{2}{|c|}{ Combined issues } \\
\hline & & & (3) & (4) & (5) & (6) \\
\hline $\begin{array}{l}\text { - Group } 1 \text { (information vs no in- } \\
\text { formation) }\end{array}$ & $\begin{array}{c}-0.538 * * \\
(0.226)\end{array}$ & $\begin{array}{c}-0.420 * * * \\
(0.133)\end{array}$ & $\begin{array}{l}-0.057 \\
(0.216)\end{array}$ & $\begin{array}{c}0.136 \\
(0.154)\end{array}$ & $\begin{array}{c}-0.324 * * \\
(0.157)\end{array}$ & $\begin{array}{l}-0.156 \\
(0.102)\end{array}$ \\
\hline Coefficient on standardized DV & $\begin{array}{c}-0.154 * * \\
(0.065)\end{array}$ & $\begin{array}{c}-0.120 * * * \\
(0.038)\end{array}$ & $\begin{array}{l}-0.016 \\
(0.062)\end{array}$ & $\begin{array}{c}0.039 \\
(0.044)\end{array}$ & $\begin{array}{c}-0.093 * * \\
(0.045)\end{array}$ & $\begin{array}{l}-0.045 \\
(0.029)\end{array}$ \\
\hline $\begin{array}{l}\text { - Group } 2 \text { (social cues vs. infor- } \\
\text { mation) }\end{array}$ & $\begin{array}{l}-0.040 \\
(0.227)\end{array}$ & $\begin{array}{c}0.065 \\
(0.134)\end{array}$ & $\begin{array}{l}-0.118 \\
(0.221)\end{array}$ & $\begin{array}{l}-0.193 \\
(0.158)\end{array}$ & $\begin{array}{l}-0.066 \\
(0.159)\end{array}$ & $\begin{array}{l}-0.069 \\
(0.103)\end{array}$ \\
\hline Coefficient on standardized DV & $\begin{array}{l}-0.012 \\
(0.065)\end{array}$ & $\begin{array}{c}0.019 \\
(0.038)\end{array}$ & $\begin{array}{l}-0.034 \\
(0.063)\end{array}$ & $\begin{array}{l}-0.055 \\
(0.045)\end{array}$ & $\begin{array}{l}-0.019 \\
(0.046)\end{array}$ & $\begin{array}{l}-0.020 \\
(0.030)\end{array}$ \\
\hline $\begin{array}{l}\text { - Group } 3 \text { (uncertainty vs. infor- } \\
\text { mation) } \\
\text { Coefficient on standardized DV }\end{array}$ & $\begin{array}{c}0.249 \\
(0.224) \\
0.071 \\
(0.064)\end{array}$ & $\begin{array}{c}0.123 \\
(0.132) \\
0.035 \\
(0.038)\end{array}$ & $\begin{array}{c}0.032 \\
(0.213) \\
0.009 \\
(0.061)\end{array}$ & $\begin{array}{c}-0.174 \\
(0.153) \\
-0.050 \\
(0.044)\end{array}$ & $\begin{array}{c}0.144 \\
(0.156) \\
0.041 \\
(0.044)\end{array}$ & $\begin{array}{c}-0.027 \\
(0.101) \\
-0.008 \\
(0.029)\end{array}$ \\
\hline Ideology (r.c. = Liberals) & & & & & & \\
\hline - Conservatives & $\begin{array}{l}-5.512 * * * \\
(0.180)\end{array}$ & $\begin{array}{c}-1.482 * * * \\
(0.148)\end{array}$ & $\begin{array}{c}-6.031 * * * \\
(0.172)\end{array}$ & $\begin{array}{c}-2.099 * * * \\
(0.188)\end{array}$ & $\begin{array}{c}-5.773 * * * \\
(0.126)\end{array}$ & $\begin{array}{c}-1.734 * * * \\
(0.118)\end{array}$ \\
\hline - Moderates/DK & $\begin{array}{l}-1.224 * * * \\
(0.289)\end{array}$ & $\begin{array}{l}-0.185 \\
(0.172)\end{array}$ & $\begin{array}{c}-2.415 * * * \\
(0.253)\end{array}$ & $\begin{array}{c}-0.758 * * * \\
(0.190)\end{array}$ & $\begin{array}{l}-1.826 * * * \\
(0.192)\end{array}$ & $\begin{array}{c}-0.433 * * * \\
(0.128)\end{array}$ \\
\hline Socio-demographics & Yes & Yes & Yes & Yes & Yes & Yes \\
\hline Census regions & Yes & Yes & Yes & Yes & Yes & Yes \\
\hline Lagged DV & No & Yes & No & Yes & No & Yes \\
\hline Issue dummy & No & No & No & No & Yes & Yes \\
\hline $\mathrm{R}^{2}$ & 0.565 & 0.849 & 0.645 & 0.819 & 0.603 & 0.832 \\
\hline $\mathrm{N}$ & 825 & 825 & 816 & 816 & 1641 & 1641 \\
\hline
\end{tabular}

Note. OLS regression coefficients with standard errors in parentheses. Dependent variable rescaled from 5 (strongly against universal healthcare / strongly in favor of border barriers) to 5 (strongly in favor of universal healthcare / strongly against border barriers). Socio-demographics include gender, age, education level and race (White only versus other categories). $* \mathrm{p}<0.1, * * \mathrm{p}<0.05, * * * \mathrm{p}<0.01$ 
Table A8. Treatment effects within ideology categories (average marginal effects based on Table 1)

(1)

Effects of Group 1 (information)

vs. Group 0 (no information) on:

- Liberals $\left(b_{1}\right)$

Conservatives $\left(\mathrm{b}_{2}\right)$

$\left|b_{1}+b_{2}\right|$

$Z$ score

$P$ value: $b_{1}=-b_{2}$
(2)

(3)

(4)

(5)

(6)

$\begin{array}{cccccc}-0.553 * & -0.411^{* *} & 0.232 & 0.364 * & -0.224 & -0.054 \\ (0.295) & (0.174) & (0.289) & (0.206) & (0.207) & (0.135) \\ & & & & & \\ -0.429 & -0.391 * & -0.437 & -0.105 & -0.416 & -0.234 \\ (0.394) & (0.232) & (0.370) & (0.264) & (0.272) & (0.177)\end{array}$

$\begin{array}{cccccc}0.98 & 0.80 & 0.21 & 0.26 & 0.64 & 0.29 \\ -1.995 & -2.766 & -0.437 & 0.773 & -1.872 & -1.294 \\ 0.046 & 0.006 & 0.662 & 0.440 & 0.061 & 0.196\end{array}$

\begin{tabular}{|c|c|c|c|c|c|c|}
\hline \multicolumn{7}{|l|}{$\begin{array}{l}\text { Effects of Group } 2 \text { (social cues) } \\
\text { vs. Group } 1 \text { (information) on: }\end{array}$} \\
\hline - Liberals $\left(b_{1}\right)$ & $\begin{array}{c}0.283 \\
(0.298)\end{array}$ & $\begin{array}{c}0.218 \\
(0.176)\end{array}$ & $\begin{array}{c}0.029 \\
(0.294)\end{array}$ & $\begin{array}{l}-0.194 \\
(0.210)\end{array}$ & $\begin{array}{l}0.208 \\
(0.210)\end{array}$ & $\begin{array}{c}0.017 \\
(0.136)\end{array}$ \\
\hline - Conservatives $\left(b_{2}\right)$ & $\begin{array}{c}-0.771 * * \\
(0.388)\end{array}$ & $\begin{array}{l}-0.309 * \\
(0.229)\end{array}$ & $\begin{array}{l}-0.427 \\
(0.386)\end{array}$ & $\begin{array}{l}-0.319 \\
(0.275)\end{array}$ & $\begin{array}{l}-0.642 * * * \\
(0.275)\end{array}$ & $\begin{array}{c}-0.333 * * \\
(0.179)\end{array}$ \\
\hline$\left|b_{1}+b_{2}\right|$ & 0.49 & 0.09 & 0.40 & 0.51 & 0.43 & 0.32 \\
\hline$Z$ score & -0.997 & -0.315 & -0.820 & -1.483 & -1.254 & -1.406 \\
\hline$P$ value (one-tailed): $b_{1}=-b_{2}$ & 0.159 & 0.376 & 0.206 & 0.069 & 0.105 & 0.080 \\
\hline \multicolumn{7}{|l|}{$\begin{array}{l}\text { Effects of Group3 (uncertainty) } \\
\text { vs. Group } 1 \text { (information) on: }\end{array}$} \\
\hline - Liberals $\left(b_{1}\right)$ & $\begin{array}{c}0.319 \\
(0.291)\end{array}$ & $\begin{array}{c}0.017 \\
(0.172)\end{array}$ & $\begin{array}{c}0.010 \\
(0.283)\end{array}$ & $\begin{array}{l}-0.290 \\
(0.202)\end{array}$ & $\begin{array}{l}0.193 \\
(0.204)\end{array}$ & $\begin{array}{l}-0.122 \\
(0.133)\end{array}$ \\
\hline - Conservatives $\left(b_{2}\right)$ & $\begin{array}{l}-0.061 \\
(0.396)\end{array}$ & $\begin{array}{c}0.145 \\
(0.233)\end{array}$ & $\begin{array}{l}-0.001 \\
(0.375)\end{array}$ & $\begin{array}{c}0.120 \\
(0.268)\end{array}$ & $\begin{array}{l}-0.091 \\
(0.274)\end{array}$ & $\begin{array}{c}0.108 \\
(0.178)\end{array}$ \\
\hline$\left|b_{1}+b_{2}\right|$ & 0.26 & 0.16 & 0.01 & 0.17 & 0.10 & 0.01 \\
\hline$Z$ score & 0.525 & 0.559 & 0.019 & -0.507 & 0.299 & -0.063 \\
\hline$P$ value (one-tailed): $H_{0}: b_{1}=-b_{2}$ & 0.300 & 0.288 & 0.492 & 0.306 & 0.382 & 0.475 \\
\hline
\end{tabular}

Note: Average marginal effects with standard errors in parentheses based on regression models in Table 1.

Formula for $Z$ score from Paternoster, Brame, Mazerolle and Piquero (1998).

$* \mathrm{p}<.1, * * \mathrm{p}<.05, * * * \mathrm{p}<.01$ (one-tailed for effects of social cues and uncertainty) 


\section{Appendix B. Question wording and information stimuli}

\section{Wave 1}

\section{Ideology}

Q: We hear a lot of talk these days about liberals and conservatives. Here is a seven-point scale on which the political views that people might hold are arranged from extremely liberal to extremely conservative. Where would you place yourself on this scale?

A: $\quad$ Extremely liberal

Liberal

Slightly liberal

Moderate; middle of the road

Slightly conservative

Conservative

Extremely conservative

Haven't thought much about this

Prior attitudes (universal healthcare)

Q: On a scale from 0 to 10 , where 0 means "strongly against" and 10 means "strongly in favor", how strongly in favor or against are you with implementing a universal healthcare system, meaning publicly-funded health coverage for all American citizens?

A: $\quad 0$ (strongly AGAINST)

$\ldots$

5 (neither against nor in favor)

...

10 (strongly IN FAVOR)

Don't know

Prior attitudes (border barriers)

Q: On a scale from 0 to 10 , where 0 means "strongly against" and 10 means "strongly in favor", how strongly in favor or against are you with expanding border barriers against illegal immigration?

A: $\quad 0$ (strongly AGAINST)

...

5 (neither against nor in favor)

$\cdots$

10 (strongly IN FAVOR)

Don't know 
Issue relevance (universal healthcare)

Q: Compared to other issues concerning for example the environment, the economy, or foreign affairs, how relevant do you believe the issue of universal healthcare is for the United States right now?

A: $\quad 0$ (not at all relevant)

...

10 (absolutely relevant)

Don't know

Issue relevance (border control)

Q: Compared to other issues concerning for example the environment, the economy, or foreign affairs, how relevant do you believe the issue of border control is for the United States right now?

A: $\quad 0$ (not at all relevant)

$\cdots$

10 (absolutely relevant)

Don't know

\section{Attention check}

Q: In this study we asked you a few questions about one of the following issues. Which one?

A: [Displayed in random order]

Universal healthcare

Border control

Climate change

Foreign affairs

I don't remember

\section{Wave 2}

Alternative measures of ideology

Q: How strongly do you agree or disagree with the following statements?

Statements presented in random order

Economic conservatism

The government should help more needy people even if it means going deeper into debt

There need to be stricter laws and regulations to protect the environment

Government regulation of business usually does more harm than good

Social conservatism

Gays and lesbians should be allowed to marry legally

Abortion should be illegal in all or most cases

The growing number of newcomers from other countries threaten traditional American customs and values

A: Strongly disagree

Somewhat disagree 
Neither agree nor disagree

Somewhat agree

Strongly agree

Don't know

\section{Treatments}

\section{Respondents assigned to universal healthcare}

\section{Group 1 (information)}

On the next screens we will ask you to read two short texts about implementing a universal healthcare system, meaning publicly-funded health coverage for all American citizens.

The information included in each text is taken only from publicly available, reliable sources.

After reading each text, we will ask you to evaluate the argument you just read.

Please take your time and read each text carefully.

Group 2 (social cues)

On the next screens we will ask you to read two short texts about implementing a universal healthcare system, meaning publicly-funded health coverage for all American citizens.

The information included in each text is taken only from publicly available, reliable sources.

However, citizens are greatly divided in their support for these arguments, with liberals and conservatives having opposite opinions on this issue.

\section{A majority of liberals are strongly in favor of introducing a universal healthcare system,} but a majority of conservatives strongly oppose universal healthcare.

After reading each text, we will ask you to evaluate the argument you just read.

Please take your time and read each text carefully.

\section{Group 3 (uncertainty)}

On the next screens we will ask you to read two short texts about implementing a universal healthcare system, meaning publicly-funded health coverage for all American citizens.

The information included in each text is taken only from publicly available, reliable sources.

However, there is an intense debate on this topic and experts strongly disagree on whether 
implementing universal healthcare would either benefit or damage the United States.

There is also a lot of uncertainty on the estimated costs of a universal healthcare system, and it is not clear what kind of impact it would have on increasing life expectancy.

After reading each text, we will ask you to evaluate the argument you just read.

Please take your time and read each text carefully.

\section{Respondents assigned to border barriers}

\section{Group 1 (information)}

On the next screens we will ask you to read two short texts about border control and expanding border barriers against illegal immigration.

The information included in each text is taken only from publicly available, reliable sources.

After reading each text, we will ask you to evaluate the argument you just read.

Please take your time and read each text carefully.

\section{Group 2 (social cues)}

On the next screens we will ask you to read two short texts about border control and expanding border barriers against illegal immigration.

The information included in each text is taken only from publicly available, reliable sources.

However, citizens are greatly divided in their support for these arguments, with conservatives and liberals having opposite opinions on this issue.

A majority of conservatives are strongly in favor of expanding border barriers against illegal immigration, but a majority of liberals strongly oppose expanding border barriers.

After reading each text, we will ask you to evaluate the argument you just read.

Please take your time and read each text carefully.

\section{Group 3 (uncertainty)}

On the next screens we will ask you to read two short texts about border control and expanding border barriers against illegal immigration.

The information included in each text is taken only from publicly available, reliable sources. 
However, there is an intense debate on this topic and experts strongly disagree on whether expanding border barriers would either benefit or damage the United States.

There is also a lot of uncertainty on the estimated costs of expanding border barriers, and it is not clear what kind of impact they would have on reducing illegal immigration.

After reading each text, we will ask you to evaluate the argument you just read.

Please take your time and read each text carefully.

\section{Information stimuli and argument evaluation}

Respondents assigned to universal healthcare (pro and anti texts presented in random order)

Pro universal healthcare argument

Universal healthcare would cost less and improve public health measures

The U.S. spends more on healthcare than any nation in the world, yet between 28 and 34 million Americans still lack care. Analyses show that universal healthcare would lower the healthcare costs for the economy, since a larger pool of people covered means more negotiating power with providers and drug companies.

A universal healthcare system could streamline the system and reduce administrative costs, passing the savings onto the taxpayer. Evidence demonstrates that people without insurance are less likely than the insured to receive preventive care. On the contrary, by giving access to healthcare for every member of society, a universal healthcare system would expand preventive care to all those in need, and would indirectly improve life expectancy.

Argument strength (Taber and Lodge 2006)

Q: How weak or strong do you believe the argument contained in this text is?

Please note: we want to know how weak or strong you believe the argument is, not whether you agree or disagree with the argument.

A: 0 (extremely WEAK)

...

10 (extremely STRONG)

\section{Anti-universal healthcare argument}

Universal healthcare would increase government debt and raise taxes

Existing U.S. government healthcare programs are already putting a huge strain on the public budget. Adding a universal healthcare program to these would amount to enormous growth in government spending. Experts estimate that introducing free healthcare for all would increase the federal budget by around $\$ 3$ trillion per year in the first 10 years of implementation. In addition, 
a universal healthcare system raises taxes.

A single government-run insurance plan would shift the financing of healthcare from premiums paid by employers and individuals to the general taxation. People may not have to pay premiums or anything at the point of service, but they will pay higher taxes, and some people would end up paying much less while others would pay much more.

Argument strength (Taber and Lodge 2006)

Q: How weak or strong do you believe the argument contained in this text is?

Please note: we want to know how weak or strong you believe the argument is, not whether you agree or disagree with the argument.

A: 0 (extremely WEAK)

$\ldots$

10 (extremely STRONG)

Respondents assigned to universal healthcare (pro and anti texts presented in random order)

Pro border barriers argument

\section{Border barriers will help safeguard the safety of our communities}

Without secure borders, no immigration reform plan can ever work. Expanding the border wall between the United States and Mexico will reduce the entry points for illegal immigrants. Illegal migration is often associated with problems such as prostitution, slavery, and violence.

Evidence shows that since building a fence in San Diego county, the illegal aliens, drug smuggling, and crime rates have gone down drastically. The experience of other countries also shows that border security works.

For decades, open borders have allowed drugs and gangs to pour into our most vulnerable communities. Expanding border barriers will help safeguard the safety of our communities and curb the flow of illegal drugs into the United States.

Argument strength (Taber and Lodge 2006)

Q: How weak or strong do you believe the argument contained in this text is?

Please note: we want to know how weak or strong you believe the argument is, not whether you agree or disagree with the argument.

A: 0 (extremely WEAK)

$\cdots$

10 (extremely STRONG) 


\section{Anti-border barriers argument}

\section{Borders barriers are a dangerous waste of money}

Border barriers will not stop illegal immigration and drug dealing. Evidence shows that walls are increasingly irrelevant since most of the drugs smuggled into the U.S. no longer arrive on the backs of those who cross illegally. Expanding the wall between the United States and Mexico will also cost a huge amount of money - an estimate ranging from $\$ 12$ to $\$ 70$ billion - that could otherwise be spent for other important issues.

In addition, expanding border fences has increased the danger associated with moving, with proportionally more and more migrants dying while trying to cross in dangerous points. Securing our borders by expanding border barriers would be a harmful waste of billions of tax dollars.

Argument strength (Taber and Lodge 2006)

Q: How weak or strong do you believe the argument contained in this text is?

Please note: we want to know how weak or strong you believe the argument is, not whether you agree or disagree with the argument.

A: 0 (extremely WEAK)

$\cdots$

10 (extremely STRONG)

\section{Posterior attitudes (universal healthcare)}

Q: $\quad$ On a scale from 0 to 10 , where 0 means "strongly against" and 10 means "strongly in favor", how strongly in favor or against are you with implementing a universal healthcare system, meaning publicly-funded health coverage for all American citizens?

A: $\quad 0$ (strongly AGAINST)

...

5 (neither against nor in favor)

...

10 (strongly IN FAVOR)

Posterior attitudes (border barriers)

Q: On a scale from 0 to 10 , where 0 means "strongly against" and 10 means "strongly in favor", how strongly in favor or against are you with expanding border barriers against illegal immigration?

A: $\quad 0$ (strongly AGAINST)

...

5 (neither against nor in favor)

...

10 (strongly IN FAVOR) 
Attention check

Q: $\quad$ Which of the following topic was mentioned in the texts you just read? Please choose one option.

A: Improving the healthcare system by implementing universal healthcare Improving the healthcare system by increasing the number of doctors Fighting illegal immigration by expanding border barriers Fighting illegal immigration by changing visa programs I don't remember 